\title{
Modelling Hazardous Distances for Large-Scale Liquid Hydrogen Pool Releases
}

\author{
P.G. Holborn, C.M Benson, J.M. Ingram
}

Explosion \& Fire Research Group, London South Bank University, London, SE1 OAA.

\begin{abstract}
An analysis has been carried out using a CFD model (FLACS) to simulate large-scale liquid hydrogen (LH2) pool releases to examine their behaviour and predict the LH2 pool size, downwind hazardous distance, and flammable mass of the hydrogen-air clouds formed for different environmental conditions and release scenarios. The FLACS pool model reproduces similar qualitative trends with regard to the effect of spill rate, spill duration and wind speed on the flammable cloud extent to those observed in the NASA WSTF experimental tests, although significant quantitative differences in the results are also apparent. FLACS simulations were also performed for a number of different transient and continuous LH2 spill release rates to predict the maximum downwind hazardous distances as a function of the $\mathrm{LH} 2$ spill release rate. The results are intended to assist with assessing the safety of future $\mathrm{LH} 2$ aircraft and airport $\mathrm{LH} 2$ storage facilities, being considered as part of the EU ENABLEH2 project.
\end{abstract}

\section{Introduction}

The high density of liquid hydrogen ( $\mathrm{LH} 2$ ), when compared with gaseous hydrogen, allows for significantly more efficient storage, transport and distribution. Consequently, liquid hydrogen, generated from renewable energy sources, can play a key role in the development of the hydrogen economy, helping to reduce greenhouse gas emissions, and address concerns over climate change. Consequently, a number of transportation systems, utilising liquid hydrogen as a fuel source, are currently under development. For example, SFBREEZE, a high-speed ferry designed for use in San Francisco Bay, will utilise a $1200 \mathrm{~kg}$ capacity LH2 tank to supply a hydrogen fuel cell engine [1]. Furthermore, LH2 is a highly efficient rocket propellant [2]. Expanded LH2 fuel supplies will therefore be required to support the future expansion of launch vehicles and spaceports. The feasibility of using LH2 in commercial aviation is also being re-examined as part of the EU ENABLEH2 [3] and NASA LH2-HFC aircraft projects [4]. The usage of liquid hydrogen in aviation will require the development of new types of aircraft and cryogenic fuel tank design, as well as the need for large-scale $\mathrm{LH} 2$ storage facilities at airports.

The wider usage of $\mathrm{LH} 2$ will require scaling-up of the current generation, storage and distribution infrastructure to meet demand. For instance, large scale LH2 carrier ships (e.g. Kawasaki $160,000 \mathrm{~m}^{3}$ ) are currently being designed to transport large quantities of LH2 generated at locations around the world to Japan [5]. Similarly the number and size of fixed LH2 storage tanks being designed and built around the world is also growing. For example, to support fuelling of NASA's SLS rocket, Exploration Ground Systems (EGS) is planning to 
build the world's largest LH2 storage tank $\left(4,732 \mathrm{~m}^{3}\right)$ at the NASA Kennedy Space Centre in Florida [6].

However, the scale-up and wider use of $\mathrm{LH} 2$ transportation and storage systems also raises fresh concerns over their safety. Leaks from LH2 storage tanks could potentially lead to the formation of large flammable hydrogen gas clouds. Should an accidental LH2 leak then occur an $\mathrm{LH} 2$ pool can form. The $\mathrm{LH} 2$ pool will vaporise to produce a flammable hydrogen gas cloud that will disperse and travel away from the spill pool. If it should encounter a remote ignition source then the cloud could ignite resulting in a flash fire or (if in a congested or confined area) a vapour cloud explosion. The flame can also propagate back to the $\mathrm{LH} 2$ pool producing a pool fire. The extent of the flammable cloud from the spill point therefore provides a means of characterising the level of threat posed by the LH2 release. It would therefore be desirable to be able to relate the extent of flammable cloud (flammable distance), and the size of the $\mathrm{LH} 2$ pool formed, to the properties of the $\mathrm{LH} 2$ release, such as the spill rate and duration, and atmospheric conditions, such as wind speed.

Unfortunately, the existing experimental test data on the behaviour of large scale LH2 spills and the flammable clouds formed is relatively limited. In the 1960s, Arthur D. Little carried out an experimental programme, for the United States Airforce, to determine the potential hazards associated with the handling and storage of LH2 [7]. Instrumentation of the tests was limited, with no measurements made of hydrogen concentration or temperature in the gas cloud formed. Instantaneous LH2 ground spills of 1.25, 32, 600 and 5000 gallons (4.7, 121,2271 and 18,927 L) formed by emptying an insulated storage vessel were examined. In terms of the larger scale releases, the 600 gallon $(2271 \mathrm{~L}) \mathrm{LH} 2$ spill demonstrated the effects of cloud dispersal, at a wind velocity of $20 \mathrm{mph}(8.9 \mathrm{~m} / \mathrm{s})$, with the visible cloud dispersing downwind along the ground for 8 seconds, before it was deliberately ignited. The largest 5000 gallon (18,927 L) LH2 spill was ignited immediately, resulting in a pool fire, so no cloud dispersion behaviour was observed for this case. Some experiments, representing a LH2 pipeline rupture, using a more continuous release of LH2 (e.g. $16 \mathrm{l} / \mathrm{min}[1.1 \mathrm{~kg} / \mathrm{s}]$ for $1 \mathrm{~min}$, wind speed $7.6 \mathrm{~m} / \mathrm{s}$ ) were also performed. In this case the visible cloud, formed by the LH2 spill, was observed to remain close to the ground over a distance of 600 feet $(183 \mathrm{~m})$ from the point of release.

A series of large scale experimental liquid hydrogen dispersion tests were carried out by NASA at the White Sands Test Facility, New Mexico, during the 1980s [8-9]. The tests were intended to provide information on large, rapid $\mathrm{LH}_{2}$ spills and the associated flammable hydrogen-air cloud dispersion behaviour that might result as a consequence of the rupture of a large scale $\mathrm{LH}_{2}$ storage facility. The experiments consisted of large ground spills of $\mathrm{LH}_{2}$ of up to $5.7 \mathrm{m3}$ ( $\sim 400 \mathrm{~kg}$ ) with spill durations varying between 35 and $120 \mathrm{~s}$. The results of these experiments suggested that rapid liquid hydrogen spills, of the type corresponding to the rupture of a storage tank, produced large flammable gas clouds which would travel along the ground for a distance of 50-100 m, before rising off the ground at an angle and dispersing below the flammable limit. In contrast, slower spills, of the type corresponding to a ruptured liquid hydrogen pipeline, were characterised by lower levels of dispersion and flammable clouds that exhibited prolonged ground level travel. 
Some large scale near ground release $\mathrm{LH} 2$ releases between two buildings were conducted by Battelle/BAM for the Euro-Quebec-Hydro-Hydrogen-Pilot-Project in the 1990s [10]. The buildings each of length $49.5 \mathrm{~m}$ and width $13.4 \mathrm{~m}$ had a separation of $23.9 \mathrm{~m}$. LH2 was released into a pan of diameter $0.4 \mathrm{~m}$ and $0.1 \mathrm{~m}$ high, located next to end of one of the buildings, from which it could spill onto a $2 \mathrm{~m}$ by $2 \mathrm{~m}$ aluminium plate, situated $0.2 \mathrm{~m}$ above the ground. A total of six experiments were carried out. The resulting hydrogen gas concentrations were monitored by sensors positioned at several locations. Unfortunately, the release rate used in each test was uncertain due to lack of metering and could only be estimated to average approximately $0.4 \mathrm{~kg} / \mathrm{s}$ over a period of around 2 minutes. There were also significant uncertainties over the prevailing wind conditions for each test and their effect upon the flammable clouds formed.

A series of large scale LH2 release tests were also carried out by Heath and Safety Laboratory, at Buxton, UK, to investigate the hazards associated will liquid spills of LH2 [11]. The tests were intended to replicate the failure of a $\mathrm{LH} 2$ hose line during a tanker refuelling operation. The tests were carried out on a $32 \mathrm{~m}$ diameter concreted pad. The LH2 (stored at 2 bara) was released at $60 \mathrm{~L} / \mathrm{min}(0.071 \mathrm{~kg} / \mathrm{s})$ via an outlet orifice diameter $26.3 \mathrm{~mm}$. The hydrogen gas cloud formed passed through an array of 30 temperature thermocouples (used to infer hydrogen concentration) which could be moved to align with the prevailing wind direction. Ground thermocouples were also used to characterise the spreading behaviour of the $\mathrm{LH} 2$ pool formed. The hydrogen dispersion behaviour and formation of liquid pool on the ground was investigated for different orientations of spill. The results for four LH2 unignited tests were reported - two horizontal releases, one located at ground level, the other at a height of $0.86 \mathrm{~m}$, and for two releases directed vertically downwards from a spill point positioned $0.1 \mathrm{~m}$ above the ground. The test results suggested the flammable gas cloud formed extended at least $9 \mathrm{~m}$ downwind of the release point. The cloud dispersion was also extremely sensitive to wind speed, with clouds becoming buoyant at wind speeds of $3 \mathrm{~m} / \mathrm{s}$ or less and staying close to the ground at wind speeds greater than $5 \mathrm{~m} / \mathrm{s}$. A LH2 pool was formed for the downward release once the substrate was sufficiently cooled. However, the horizontal release of $\mathrm{LH} 2$ at $60 \mathrm{l} / \mathrm{min}, 0.86 \mathrm{~m}$ above ground resulted in total evaporation, with no evidence of rainout or an $\mathrm{LH} 2$ pool being formed.

CFD modelling of large-scale LH2 spills has primarily focused on model validation and comparisons with the available experimental data. Middha et al. [12] used the FLACS CFD (pool) model to simulate LH2 pool spread and gas cloud dispersion behaviour for the NASA White Sands Experiments - Test 6 (as reported in [8]). The predicted hydrogen concentration results (assuming stable atmospheric conditions) were found to be in good agreement with the peak concentrations observed at several instrument tower sensor locations in the test. However, they also found that the predicted hydrogen concentration was strongly underestimated at one of the sensor locations (tower 7 - height $9.4 \mathrm{~m}$ ). To improve agreement with experiment, a "meandering" wind model [13-14] was used in [12] to simulate wind gust effects. The FLACS pool model was also used to predict the variation of the $\mathrm{LH} 2$ pool radius and evaporation rate. On the basis of their study, the authors concluded that the FLACS pool model provides an efficient and accurate tool for investigating accidental release scenarios involving cryogenic liquids such as $\mathrm{LH} 2$. 
Ichard et al. [15] also used FLACS to simulate liquid hydrogen releases for two of the test performed at HSL Buxton, UK, in 2010: Test 6 - a vertical downward release $100 \mathrm{~mm}$ above the ground and Test 7 - a horizontal release $860 \mathrm{~mm}$ above the ground. In order to better represent two-phase (gas/liquid) flow behaviour they used a Homogeneous Equilibrium Model (HEM) which they implemented in FLACS, assuming both phases were in local thermal and kinematic equilibrium (this effectively treats inter-phase transport as if it occurs at an infinitely fast rate). In the HSL tests modelled, the LH2 (stored at 2 bara) was released at $60 \mathrm{~L} / \mathrm{min}(0.071 \mathrm{~kg} / \mathrm{s})$ via an outlet orifice diameter $26.3 \mathrm{~mm}$. In order to account for uncertainty in $\mathrm{LH}_{2}$ release source term (i.e. the fraction of liquid flashing to vapour) five different gas mass fractions were modelled at the leak outlet. The source term best matching the experimental release behaviour in Test 7 was identified (corresponding to a gas mass fraction at the outlet of 0.65 ). For Test 6 the FLACS Pool model was used to simulate the spread and vaporisation of $\mathrm{LH} 2$ on the ground. The effect of including or neglecting $\mathrm{O} 2$ and $\mathrm{N} 2$ condensation was also examined. The results suggested that the process of air condensation could be neglected for Test 7 , but could have a significant effect on the temperature field for Test 6 (i.e. for a release close to the ground) releasing energy and causing the hydrogen gas cloud to become more buoyant and reach higher altitudes.

The ADREA-HF CFD code has been applied to model the BAM, NASA WSTF and HSL experimental LH2 spill tests. Statharas et al. [10] modelled BAM experimental test 5 . They found that ground heating had a strong effect upon the dispersion of the $\mathrm{LH} 2 \mathrm{pool}$ and that dispersion of the gas cloud exhibited dense gas behaviour close to the spill and significant buoyant behaviour further away. They also noted wind direction had a significant effect upon the cloud dispersion behaviour due to the shielding effect of the surrounding buildings. Venetsanos and Bartzis [16] applied ADREA-HF to model NASA test 6 . They found that modelling $\mathrm{LH} 2$ source as a downward two-phase jet, with a pond fence, and contact heat transfer to the ground produced the best agreement with experiment. However, they found that gas concentrations were overestimated at lower levels and underestimated at higher levels and that the model was unable to reproduce the sudden changes in cloud structure observed experimentally or the high concentration levels measured at tower 7 .

Giannissi et al. [17] used ADREA-HF to simulate HSL LH2 spill tests 5, 6 and 7, examining the effect of atmospheric humidity, and two phase models - HEM (no slip) and NHEM (with slip so two phases can have different velocities) - upon gas dispersion behaviour. They concluded that simulations including both humidity and slip effect produced the results that were in better agreement with experiment. In a later paper, Giannissi and Venetsanos [18] compared the results obtained for Test 7 with and without sub-models for water vapour, nitrogen and oxygen phases and no slip, algebraic slip and momentum slip models. Their results indicated that the buoyancy of the gas cloud was increased and the downwind flammable distance to the LFL was reduced significantly (by as much as $35 \%$ ) when the phase change effects of water vapour (and to a lesser extent the components of air) were taken into account.

Verfondern and Dienhart $[19,20]$ describe the LAuV code, developed by FZJ, which can be used to simulate the spreading and vaporisation behaviour of a $\mathrm{LH} 2$ pool by solving the 2-D shallow-layer equations for pool height and velocity. LAuV was used to simulate the LH2 pool formed for NASA Test 6 predicting a maximum pool radius of $6.5 \mathrm{~m}$ - around double 
that inferred from the experimental test results (although the predicted vaporisation time of $43.5 \mathrm{~s}$ was very close to that estimated from the test). The discrepancy was attributed to the effect of percolation of liquid into the sand, furrowing of the test site increasing surface contact area and the $\mathrm{LH} 2$ spill splashing from a deflection plate before hitting the ground.

Jin, Liu and co-workers have employed a model for predicting LH2 spill dispersion behaviour, using ANSYS FLUENT CFD. Both the liquid and gas phases of hydrogen are represented and assumed to be in thermal equilibrium. The mass transfer between the two phases is described using Lee's model, with the mass transfer coefficient "tuned"(to a value of 0.25 ) using the WSFT NASA- 6 experimental test results. The model was validated using the largescale NASA WSTF Test 6 experiment and found to produce acceptable agreement. They have subsequently published a series of papers modelling the flammable gas clouds formed by liquid hydrogen spills and examining the effect of a range of different factors including: ground temperature, wind speed, and ambient temperature [21]; the evolution of the flammable cloud with time and role of turbulent diffusion [22]; different LH2 source conditions (spill amount, duration, and liquid mass fraction) [23]; air humidity [24]; the effect of dikes positioned around the LH2 spill [25]; the effect of continuous LH2 spills [26]; and dilution of the flammable vapor cloud by wind and turbulence [27].

Shao et al. [28] have also used ANSYS FLUENT CFD to investigate the dispersion history of flammable clouds formed by LH2 spills under different weather conditions. Their model employed a Non-Homogeneous Equilibrium Model (NHEM) approach to represent the twophase hydrogen release. Mass transfer between the two phases was again described using Lee's model and they adopted mass transfer coefficient value of 0.25 used by Jin et al. [21]. However, in this case the LH2 liquid phase was represented using a particle slip model, with an estimated diameter of $10 \mu \mathrm{m}$. The model was validated using the WSFT NASA-6 experimental test results. It was then used to examine the effect of ambient temperature, wind speed and atmospheric pressure upon dispersion behaviour. They found that increasing wind speed enhanced the dispersion of the cloud, but was impeded by increasing atmospheric pressure.

Jäkel et al. [29] have also developed a CFD model (implemented in the ANSYS-CFD), for liquid hydrogen releases and the resulting gas cloud dispersion behaviour, which they validated against the NASA WSTF (Test 6) and HSL (Tests 5, 6, 7 and 10) experimental tests. A HEM approach was adopted to model the liquid and gas hydrogen phases. Surface heat transfer due to vaporization of liquid hydrogen was modelled using correlations for the nucleate, transition and film boiling regimes. The effect of water vapour condensation was also considered and found to slightly increase the buoyancy of the resulting hydrogen gas cloud. On the basis of their results they concluded that the predictions from their model (LH2 pool size and hydrogen and temperature distributions) were qualitatively consistent with the available experimental test data and modelling results obtained by other researchers. However, there were also significant quantitative deviations which they attributed to uncertainties in relation to the specification of ground and atmospheric boundary conditions in the available experimental tests.

Hansen [30] has recently shown that LH2 releases can exhibit dense gas behaviour under certain conditions. The FLACS CFD code was used to make a comparison between the LH2 
and LNG hazard distances predicted for horizontal and downward releases from a pressurised tank ( 5 barg) through a $10 \mathrm{~mm}$ diameter instrument connection, in a $2 \mathrm{~m} / \mathrm{s}$ wind. As a result of dense gas behaviour, the LFL-distances found for the LH2 releases were significantly longer than for comparable LNG releases. In the case of the horizontal release the hazardous distance to the 4\% LFL was $122 \mathrm{~m}$ - five times that found for LNG, whilst for the downward release it was $67 \mathrm{~m}$ - double that found for LNG.

Based upon these previous studies, only a limited amount of information is available examining the scaling behaviour of the extent of flammable gas cloud and the size of the LH2 pool formed. In this paper, an analysis has therefore been carried out, using a CFD model (FLACS), to examine and predict the behaviour of LH2 spill releases in terms of the extent of flammable cloud (maximum downwind hazardous distance), peak flammable mass and the $\mathrm{LH} 2$ pool size, to look at how they scale with the size of the LH2 release spill rate.

This work forms part of a programme of work being carried out for the EU ENABLEH2 project, examining the feasibility of using LH2 in commercial aviation [3]. The usage of LH2 in aviation will require the development of new types of aircraft and cryogenic fuel tank design, as well as the need for the provision of large-scale LH2 storage facilities at airports. The results are intended to assist with assessing the safety of future LH2 aircraft and largescale airport LH2 storage facilities, being considered as part of ENABLEH2.

\section{Method - The FLACS CFD Model}

The numerical simulations were performed using the FLACS CFD model. FLACS was originally developed in the 1980 and 90s for use in the Oil and Gas industry. It provides capabilities for carrying out safety studies by simulating accident scenarios involving fluid flow behaviour in complex 3D geometries by modelling flammable gas hazard effects such as:

- Dispersion of flammable gases

- Gas explosions and blast waves

- Pool and jet fires

FLACS is a structured Cartesian grid, finite volume CFD code. The code solves the compressible conservation equations for mass, momentum, enthalpy, mass fraction of chemical species, turbulent kinetic energy and dissipation rate of turbulent kinetic energy [31]. The numerical treatment used in FLACS solver employs a second order scheme in space, and a first/second order in time. The pressure and velocity fields are coupled via the SIMPLE solution algorithm [32]. A standard $k-\varepsilon$ turbulence model is also utilised incorporating modifications for generation of turbulence behind sub-grid obstacles and turbulent wall functions.

FLACS employs the Porosity/Distributed Resistance method to model the turbulence generated by subgrid scale objects [31]. This allows for the efficient simulation of gas dispersion behaviour in complex geometries using relatively coarse numerical grids. 
The convergence of solutions in FLACS is managed through the Courant-Friedrich-Levy (CFL) number [31]. An adaptive time step routine is used, with the time step adjusted to meet CFL number stability criteria based upon both the speed of sound (CFLC) and the fluid flow velocity (CFLV). Each time step length is selected so that both sound waves and the fluid may propagate only a limited distance, equal to the average control volume length multiplied by the CFLC/CFLV number.

\section{Atmospheric Dispersion Modelling}

The stability of the atmospheric boundary layer plays an important role in determining the level of turbulence and hence the resulting gas dispersion behaviour. In FLACS, the atmospheric stability is characterised by using the concept of the Pasquill-Gifford stability class (A to F) [31]. Here, Pasquill classes A-C correspond to unstable, D neutral, and E-F stable atmospheric conditions [33]. Under stable atmospheric conditions turbulent fluctuations and mixing behaviour are damped. Hence the level of dispersion is reduced and high gas concentrations can persist over greater distances than is the case for unstable conditions.

Atmospheric boundary layer flows are modelled in FLACS by introducing profiles for wind velocity, temperature and turbulence on the flow inlet boundaries [31]. Buoyancy effects are accounted for by introducing additional source terms in the momentum and turbulence model equations.

The wind inlet velocity profiles are assumed to be logarithmic in form and are specified as a function of the Monin-Obukhov length, $L(\mathrm{~m})$, and the surface roughness length, $z_{0}(\mathrm{~m})$ :

$U(z)=\frac{u_{*}}{\kappa}\left(\ln \left(\frac{z}{z_{0}}\right)-\psi_{u}(z)\right)$

where $\kappa$ is the von-Karman constant $(-), z$ is the height above the ground $(\mathrm{m})$, and $u *$ is the friction velocity $(\mathrm{m} / \mathrm{s})$ :

$$
u_{*}=\frac{U_{0} \kappa}{\ln \left(\frac{z_{r e f}}{z_{0}}\right)-\psi_{u}\left(z_{r e f}\right)}
$$

where $U_{0}$ is the wind velocity $(\mathrm{m} / \mathrm{s})$ at the reference height, $z_{r e f}(\mathrm{~m})$. The stability function $\psi_{u}$ $(-)$ is a function of $z$ and $L$ :

$$
\psi_{u}(z)= \begin{cases}2 \ln \left(\frac{1+\xi}{2}\right)+\ln \left(\frac{1+\xi^{2}}{2}\right)-2 \arctan (\xi)+\frac{\pi}{2} & \text { for } L<0 \\ -17\left(1-\exp \left(-0.29 \frac{z}{L}\right)\right) & \text { for } L>0\end{cases}
$$

and

$$
\psi_{u}(z)=0 \quad \text { for Pasquill Class D }
$$

Where 
$\xi=\left(1-\frac{16 z}{L}\right)^{1 / 4}$

In FLACS, the Monin-Obukhov length scale is estimated by relating it to the specified Pasquill-Gifford stability class using an approach based on work by Golder [34]. By using a table relating the Pasquill Class to specific values for two parameters $L_{s}(\mathrm{~m})$ and $z_{s}(\mathrm{~m})$ the Monin-Obukhov length, $L(\mathrm{~m})$, can then be estimated using the relation:

$\frac{1}{L}=\frac{1}{L_{s}} \log \frac{z_{0}}{z_{s}}$

The temperature boundary profile is assumed to be uniform. The boundary profiles used for turbulent kinetic energy $(k)$ and dissipation $(\varepsilon)$ are taken from Han et al. [35].

Further details of the wind boundary model implemented in FLACS can be found in [31]. The model has been tested for a wide variety of scenarios including buoyant and dense gas releases [13-14].

\section{The FLACS Pool Model}

The FLACS pool model [31] allows the deposition and spread of a pool of liquid from a spill onto the ground simulated and the release source term to the gas dispersion model to be calculated. The model was originally developed for use with LNG spills but has also been applied to liquid hydrogen releases $[12,15]$. In the FLACS pool model the liquid (incompressible) and gaseous (compressible) states are modelled separately. Hence, the model does not consider or employ relations expressing the thermodynamic state or slip velocity between two phases co-existing in the same control volume. Treatment of the liquid phase is restricted to the pool. This acts as a source term to the gaseous phase via heat and mass transfer due evaporation from the pool.

The behaviour of the spreading liquid pool is approximated by solving the shallow-water equations on a two-dimensional Cartesian grid along the ground (identical to the $x-y$ grid defined in FLACS) and assuming that the pool, properties (velocity, temperature etc.) are uniform across the height of the pool. The pool model solves conservation equations for mass (expressed in terms of spill height), momentum (spill velocity) and enthalpy for the pool. The spill height, $h(\mathrm{~m})$ is given by the equation:

$\frac{\partial h}{\partial t}+\frac{\partial h u_{i}}{\partial x_{i}}=\frac{\dot{m}_{L}-\dot{m}_{V}}{\rho_{l}}$ 
while the momentum equation is:

$\frac{\partial h u_{i}}{\partial t}+u_{j} \frac{\partial h u_{i}}{\partial x_{j}}=F_{g, i}+F_{\tau, i}$

where $\dot{m}_{L}$ is the liquid mass spill rate per unit area $\left(\mathrm{kg} / \mathrm{m}^{2} / \mathrm{s}\right), \dot{m}_{V}$ is the mass vaporisation rate per unit area $\left(\mathrm{kg} / \mathrm{m}^{2} / \mathrm{s}\right), \rho_{l}$ is the density of the liquid $\left(\mathrm{kg} / \mathrm{m}^{3}\right)$ and $u_{i}$ is the velocity component of the spill $(\mathrm{m} / \mathrm{s})$ in direction $x_{i}$. The terms on the right-hand side of the momentum equation $\left(\mathrm{m}^{2} / \mathrm{s}^{2}\right)$ represent the effects of gravity, and the shear stress between the pool and the substrate, respectively:

$$
\begin{aligned}
& F_{g, i}=h g \Delta \frac{\partial(h+z)}{\partial x_{i}} \\
& F_{\tau, i}=\frac{1}{8} f_{f} u_{i}\left|u_{i}\right|
\end{aligned}
$$

where $g$ is gravitational acceleration $\left(\mathrm{m} / \mathrm{s}^{2}\right), \Delta$ is a factor $(-)$ that equals unity for pools on solid ground and $\left(1-\rho_{l} / \rho_{w}\right)$ for pools on water, $z$ is the elevation of the ground $(m)$, which allows the effects of sloping terrains, obstacles and embankments to be accounted for, and $f_{f}$ is a friction factor between the pool and substrate (-) which is calculated for either laminar or turbulent flow regimes (whichever is greater). Note that here, and in what follows "(-)" denotes an expression with dimensionless units. In the laminar regime the laminar friction factor is given by:

$f_{f, l a m}=\frac{64}{4 \mathrm{Re}_{h}}$

Where $\mathrm{Re}_{\mathrm{h}}$ is the Reynolds number for the pool fluid flow (-). For turbulent flows the turbulent friction factor is given by:

$$
f_{f, \text { turb }}= \begin{cases}\left\{-1.8 \log \left(\frac{1.72}{R e_{h}}+\left(\frac{\varepsilon_{g}}{12 h}\right)^{1.11}\right\}^{-2}\right. & \text { if } \frac{\varepsilon_{g}}{h}<0.2 \\ 0.125\left(\frac{\varepsilon_{g}}{h}\right)^{1 / 3} & \text { if } \frac{\varepsilon_{g}}{h} \geq 0.2\end{cases}
$$

Where $\varepsilon_{g}$ is the ground roughness $(m)$. The friction factor is then taken to be:

$f_{f}=\max \left(f_{f, l a m}, f_{f, t u r b}\right)$

The transport equation for the specific enthalpy of the pool, $\theta(\mathrm{J} / \mathrm{kg})$, is given by:

$$
\frac{\partial h \theta}{\partial t}+u_{i} \frac{\partial h \theta}{\partial x_{i}}=\frac{\dot{m}_{L}}{\rho_{l}}\left(\theta_{L}-\theta\right)+\frac{1}{\rho_{l}}\left(\dot{q}_{c}+\dot{q}_{\text {rad }}+\dot{q}_{g}+\dot{q}_{\text {evap }}\right)
$$


where $\theta_{L}$ is the liquid enthalpy $(\mathrm{J} / \mathrm{kg})$, the first term on the right hand side is the enthalpy due to spill, $\dot{q}_{c}$ is the convective heat transfer between the pool and the surrounding air $\left(\mathrm{J} / \mathrm{m}^{2} / \mathrm{s}\right), \dot{q}_{\text {rad }}$ is the radiative heat transfer from the surroundings and the sun $\left(\mathrm{J} / \mathrm{m}^{2} / \mathrm{s}\right), \dot{q}_{g}$ is the heat transfer to the pool from the substrate $\left(\mathrm{J} / \mathrm{m}^{2} / \mathrm{s}\right)$, and $\dot{q}_{\text {evap }}$ is the heat loss due to evaporation $\left(\mathrm{J} / \mathrm{m}^{2} / \mathrm{s}\right)$.

For pools formed of liquid hydrogen, heat transfer to the pool is typically dominated by heating from the substrate, given by:

$\dot{q}_{g}=\left(\dot{q}_{g, \text { cond }}^{3}+\dot{q}_{g, \text { conv }}^{3}\right)^{1 / 3}$

where, for solid and rough ground and for all ground types under non-boiling conditions, the conductive heat transfer between the pool and substrate $\left(\mathrm{W} / \mathrm{m}^{2}\right)$ is given by:

$$
\dot{q}_{g, \text { cond }}= \begin{cases}\frac{\lambda_{g}\left(T_{g}^{\infty}-T_{p}\right)\left(1.5-0.25\left(t-t_{g w}\right)\right)}{\sqrt{\pi \alpha_{g}}} & \text { if } t<4 s \\ \frac{\lambda_{g}\left(T_{g}^{\infty}-T_{p}\right)}{\sqrt{\pi \alpha_{g}\left(t-t_{g w}\right)}} & \text { if } t \geq 4 s\end{cases}
$$

where $\lambda_{g}$ is the thermal conductivity of the ground substrate $(\mathrm{W} / \mathrm{m} / \mathrm{K}), T_{g}{ }^{\infty}$ is the ground temperature at an infinite depth below the pool - equal to the ground temperature before it is wetted by the pool $(\mathrm{K}), T_{p}$ is the pool temperature $(\mathrm{K}), t_{g w}$ is the point in time when the ground is wetted (s) and $\alpha_{g}$ is the thermal diffusivity of the ground $\left(\mathrm{m}^{2} / \mathrm{s}\right)$.

The convective heat transfer between the pool and substrate $\left(\mathrm{W} / \mathrm{m}^{2}\right)$ is given by:

$\dot{q}_{g, \text { conv }}=0.0133 R e_{h}^{0.69} \operatorname{Pr}_{l}^{0.4} \frac{\lambda_{l}}{h}\left(T_{g}^{s}-T_{p}\right)$

where $\lambda_{l}$ and $P r_{l}$ are the conductivity $(\mathrm{W} / \mathrm{m} / \mathrm{K})$ and the Prandtl number of the pool liquid, $R_{h}$ is the local Reynolds number of the spreading pool, and $T_{g}{ }^{s}$ is the ground temperature at the surface (K) given by:

$T_{g}^{s}=T_{g}^{\infty}+2 \frac{\dot{q}_{s}}{\lambda_{g}} \sqrt{\frac{\alpha_{g}\left(t-t_{g w}\right)}{\pi}}$

The convective heat transfer between the pool and the surrounding air, is based on boundary layer theory and is given by:

$\dot{q}_{c}=\frac{\rho c_{\mu}^{1 / 4} k^{1 / 2} c_{p}\left(T-T_{p}\right)}{T^{+}}$

Where $\rho$ is the gas density $(\mathrm{kg} / \mathrm{m} 3), C_{\mu}$ is the constant in the $k-\varepsilon$ turbulence model equation $(-), k$ is the turbulent kinetic energy $\left(\mathrm{m}^{2} / \mathrm{s}^{2}\right), c_{p}$ is the specific heat capacity at constant pressure of the gas $(\mathrm{J} / \mathrm{kg} / \mathrm{K}), T$ is the gas temperature $(\mathrm{K})$, and $T^{+}$is the dimensionless temperature (-) used in the models wall functions, given by: 
$T^{+}= \begin{cases}\operatorname{Pr} y^{+} & \text {if } y^{+}<E^{+} \\ E^{+} \operatorname{Pr}+\frac{P r_{T}}{\kappa} \ln \left(\frac{y^{+}}{E^{+}}\right) & \text {if } y^{+} \geq E^{+}\end{cases}$

Where $\operatorname{Pr}$ and $\operatorname{Pr}_{\mathrm{T}}$ are respectively the laminar and turbulent Prandtl numbers for the gas (-), $E^{+}$is the wall function constant $(-)$and $y^{+}$is the dimensionless wall distance (-) given by:

$y^{+}=\frac{\rho C_{\mu}^{1 / 4} k^{1 / 2} y}{\mu}$

Where $y$ is the wall distance $(\mathrm{m})$ and $\mu$ is the dynamic viscosity (Pa s).

The radiative heat transfer from both the surroundings and the sun to the pool is given by:

$\dot{q}_{\text {rad }}=(1-\omega) \dot{q}_{\text {sun }}+\varepsilon \sigma T^{4}-\varepsilon_{p} \sigma T_{p}^{4}$

Where $\omega$ is the albedo of the pool (-), $\varepsilon$ and $\varepsilon_{p}$ are the emissivity of the gas and the pool (-), $\sigma$ is the Stefan-Boltzmann constant $\left(\mathrm{J} / \mathrm{m}^{2} / \mathrm{s} / \mathrm{K}^{4}\right)$ and $\dot{q}_{\text {sun }}$ is the radiative heat flux from the sun to the pool $\left(\mathrm{J} / \mathrm{m}^{2} / \mathrm{s}\right)$.

The mass vaporisation rate of liquid from the pool, $\dot{m}_{v}\left(\mathrm{~kg} / \mathrm{m}^{2} / \mathrm{s}\right)$ is determined by the convective and boiling mass transfer rates:

$\dot{m}_{v}=\dot{m}_{c}+\dot{m}_{\text {boil }}$

Where the convective mass transfer from the pool to the gas $\left(\mathrm{kg} / \mathrm{m}^{2} / \mathrm{s}\right)$ is given by:

$\dot{m}_{c}=\frac{\rho C_{\mu}^{1 / 4} k^{1 / 2} \frac{p_{0}}{R T_{p}}\left(X-X_{s a t}\right)}{X^{+}}$

$X$ and $X_{\text {sat }}$ are the mole fraction of the evaporated liquid in the air $(\mathrm{mol} / \mathrm{mol})$ and the saturated mole fraction of evaporated liquid in the air at the same temperature as the pool surface $(\mathrm{mol} / \mathrm{mol})$ and $X^{+}$is given by:

$X^{+}= \begin{cases}\operatorname{Sc} y^{+} & \text {if } y^{+}<E^{+} \\ E^{+} \operatorname{Sc}+\frac{S c_{T}}{\kappa} \ln \left(\frac{y^{+}}{E^{+}}\right) & \text {if } y^{+} \geq E^{+}\end{cases}$ 
and $S c$ and $S c_{T}$ are respectively the laminar and turbulent Schmidt numbers for the gas (-).

The boiling mass transfer rate from the pool $\left(\mathrm{kg} / \mathrm{m}^{2} / \mathrm{s}\right)$ is given by:

$\dot{m}_{\text {boil }}=\max \left\{\frac{\dot{q}_{g}+\dot{q}_{c}+\dot{q}_{r a d}}{\Delta h_{f g}}-\dot{m}_{c}, 0\right\}$

Where $\Delta h_{f g}$ is the heat of evaporation of the pool liquid $(\mathrm{J} / \mathrm{kg})$

The heat transfer due to evaporation from the pool $\left(\mathrm{J} / \mathrm{m}^{2} / \mathrm{s}\right)$ is then given by:

$\dot{q}_{\text {evap }}=-\left(\dot{m}_{c}+\dot{m}_{\text {boil }}\right) \Delta h_{f g}$

For further details about the FLACS Pool Model see [31].

Hansen at al. [14] carried out a validation of FLACS pool model against experimental data sets from the model evaluation database for LNG vapour dispersion. They concluded that FLACS successfully meets the quantitative criteria for LNG vapour dispersion model validation specified in the model valuation protocol [36].

\section{NASA White Sands Experimental Tests}

A series of large scale experimental liquid hydrogen dispersion tests were carried out by NASA at the White Sands Test Facility (WSTF), New Mexico, during the 1980s [8-9]. The experiments consisted of large ground spills of $\mathrm{LH}_{2}$ of up to $5.7 \mathrm{~m}^{3}(\sim 400 \mathrm{~kg}$ ) with durations of approximately $35-120 \mathrm{~s}$. The tests were intended to provide information on large, rapid $\mathrm{LH}_{2}$ spills and the associated flammable hydrogen-air cloud dispersion behaviour that might result as a consequence of the rupture of a large scale $\mathrm{LH}_{2}$ storage facility. Some tests for longer duration spills were also carried out to try to replicate the behaviour of smaller/slower releases, corresponding to the rupture of a $\mathrm{LH}_{2}$ pipeline.

Liquid hydrogen, stored in a $5.7 \mathrm{~m}^{3}$ Dewar, was transported to the spill site, through a 15.5 $\mathrm{cm}$ diameter, $30 \mathrm{~m}$ long spill line, where it was released, via a downward facing diffuser (approximately $0.5 \mathrm{~m} \times 0.5 \mathrm{~m}$ in area), into a $9.1 \mathrm{~m}$ diameter spill pond, formed from a compacted sand base and earthen sides $0.6 \mathrm{~m}$ high. A $1.2 \mathrm{~m} \times 1.2 \mathrm{~m}$ steel plate $(1.27 \mathrm{~cm}$ thick) was located directly below the diffuser to prevent erosion of the spill point.

Nine, $19.5 \mathrm{~m}$ high, instrumented towers were located "downwind" of the centre of the spill pond $\left(1,2\right.$ and 3 at a radius of $9.1 \mathrm{~m}, 45^{\circ}$ apart, 4, 5, and 6 at a radius of $18.3 \mathrm{~m}, 45^{\circ}$ apart, and 7,8 and 9 positioned a distance $33.8 \mathrm{~m}$ in a straight line from the spill origin and spaced $22.5^{\circ}$ apart). The instruments on each tower were used to collect data on temperature, hydrogen concentration and turbulence levels. Hydrogen sampling bottles were mounted (in clusters of eight) at heights of 1,9.4 and $18.6 \mathrm{~m}$ on towers 1, 3 and 5, and at heights of $9.4 \mathrm{~m}$ and $18.6 \mathrm{~m}$ on the remaining towers, apart from tower 2 where they were located at heights of $1 \mathrm{~m}, 6.7 \mathrm{~m}$ and $13.1 \mathrm{~m}$. The bottles were opened individually, at pre-determined 
times, during the course of each test. The three towers located on the centre line $(2,5$ and 8) were fitted with UVW turbulence indicators (anenometers).

Details of the seven LH2 spill tests carried out and results obtained for some of the tests (primarily Test 6) were initially presented in [8], but were later reported in revised form in [9]. Thus, for example, the mean wind speed for Test 6 was initially reported as $2.2 \mathrm{~m} / \mathrm{s}$, but was later revised to $1.75 \mathrm{~m} / \mathrm{s}$. Variation in the prevailing wind direction during the tests meant that the direction of travel of the gas cloud was typically orientated at an angle relative to the central line of the instrumented towers $(2,5$ and 8$)$. Hence, the gas cloud did not necessarily pass through the instrument towers.

The most extensive set of test results reported (hydrogen concentration versus time at different sensor locations) was obtained for Test 6 . Hence, data from Test 6 has served as the main basis for model comparison. Results were also reported in [9] for farthest downwind distance and height of the flammable cloud, the time to vaporization of the $\mathrm{LH} 2$ pool, and the duration of the visible cloud for many of the spill tests.

\section{Simulation Details}

The initial validation simulations were performed on a domain $200 \mathrm{~m} \times 60 \mathrm{~m} \times 80 \mathrm{~m}$ in the $\mathrm{X}$, $\mathrm{Y}$ and $\mathrm{Z}$ directions ( $-30 \mathrm{~m}$ to $170 \mathrm{~m},-30 \mathrm{~m}$ to $30 \mathrm{~m}, 0$ to $80 \mathrm{~m}$ ). The "standard" grid employed had a total of 177,284 cells $(82 \times 47 \times 46$ cells). In the pool region a grid cell size of $0.5 \mathrm{~m}$ was used in the $X$ and $Y$ directions and $0.12 \mathrm{~m}$ in the $Z$ direction. Outside this region the grid cell size was increased, by using an expansion factor of 1.2, and setting a maximum grid cell size of $4 \mathrm{~m}$. A finer "hi-res" grid of 924,000 cells $(150 \times 80 \times 77$ cells) was also used to test the grid sensitivity of the results, with a smallest grid cell size (in the pool region) of $0.25 \mathrm{~m}$ in the $X$ and $Y$ directions and $0.06 \mathrm{~m}$ in the $Z$ direction, and a maximum cell size of $2 \mathrm{~m}$. For subsequent simulations the size of the domain and number of grid cells was increased, firstly only in the X-direction, to $400 \mathrm{~m} \times 60 \mathrm{~m} \times 80 \mathrm{~m}(82 \times 47 \times 46-285,384$ cells $)$ and then to $400 \mathrm{~m} \times 80 \mathrm{~m} \times 80 \mathrm{~m}(169 \times 74 \times 48-600,288$ cells $)$ in the $X, Y$ and $Z$ directions to allow the simulation of the larger flammable clouds and LH2 pool areas that are produced (without a pool fence) for higher spill rates and longer spill durations.

For the initial base-line simulations of NASA WSTF Test-6, the wind speed was set to 1.75 $\mathrm{m} / \mathrm{s}$ at a height of $10 \mathrm{~m}$. The wind direction used in the simulation was aligned to run along the positive $x$-axis (wind direction $270^{\circ}$ ). A set of monitor points was defined to represent the sensors in the NASA Tests located on instrument tower 2 ( $1 \mathrm{~m}$ high), tower 5 ( $1 \mathrm{~m}$ and $9.4 \mathrm{~m}$ high) and tower 7 (9.4 $\mathrm{m}$ high). The direction of the prevailing wind during Test 6 was orientated at an angle relative to the central line of the instrumented towers (2, 5 and 8). An additional set of monitor points were also therefore introduced into the simulation with the instrument tower sensor $x$ and $y$ positions translated to replicate the direction of the prevailing wind being at an angle of $24^{\circ}$ (midpoint of wind variation range indicated in [9]) to the centre line of the instrumented tower. Although FLACS has the capability to model different wind orientations, this would have required the use of a larger simulation domain (with increased run times) and multiple runs. Representing the change in wind direction by shifting the relative position of the monitor points, was more efficient and enabled the 
effect of multiple wind directions to be simulated using a single run. The results obtained are expected to be the same.

Values for CFLC $=20$ and CFLV $=1$ were used in the simulations. The ambient temperature was set to $15^{\circ} \mathrm{C}$. The ground roughness length for the wind profile was set to $3 \mathrm{~mm}$. The Pasquill stability class was set to class F - stable (produced best match in Middha et al. [12]). The wind profile parameter values used in the simulation (corresponding to class $\mathrm{F}$ ) were $L_{s}$ $=-31.323 \mathrm{~m}$ and $z_{s}=19.36 \mathrm{~m}$ [31]. The pool model spill point was set at the origin $(0,0,0)$. The inlet boundary (type WIND) was defined at $30 \mathrm{~m}$ upwind of this point. A pool fence, 0.6 $\mathrm{m}$ high, was defined at radius of $4.25 \mathrm{~m}$ from the spill point. This was aligned with the grid and thickened in the horizontal direction, making it two grid cells wide, to ensure it would act as a solid obstruction and would not allow dispersion of the cloud through the fence. The thermal conductivity and thermal diffusivity of the ground used in the pool model were set to $3.72 \mathrm{~W} / \mathrm{m} / \mathrm{K}$ and $1.45 \times 10^{-6} \mathrm{~m}^{2} / \mathrm{s}$, to replicate the thermal properties of wet coarse sand [37]. The ground was also assumed to be adiabatic outside of the pool region. Fig. 1 illustrates the boundary conditions, the domain and the grid used in the initial base-line simulations.

The pool release was started after 10 seconds of simulation time to allow the wind field to become established. Liquid hydrogen in the pool model was released at $9.5 \mathrm{~kg} / \mathrm{s}$ for a duration of $38 \mathrm{~s}$. In order to comply with FLACS Best Practice User Guidelines (so as to adequately resolve the pool region and produce a circular pool shape) the radius of the leakage area used in the pool model was set equal to the length of 3 grid cells $(1.5 \mathrm{~m}$ for the "standard" grid, $0.75 \mathrm{~m}$ for the "hi-res" grid), rather than the physical dimension of the experimental diffuser used in the tests. As a limiting case to examine the effect of the largest possible $\mathrm{LH} 2$ pool (i.e. a conservative assumption with regard to the formation of the liquid pool and the subsequent dispersion behaviour), it was assumed that all of the LH2 release was deposited into the $\mathrm{LH} 2$ pool and the effects of flash vaporisation were neglected. Such releases may approximate conditions where $\mathrm{LH} 2$ is stored at low gauge pressures above atmospheric (such as is the case with LH2 tanks to be used in aircraft) and there is consequently expected to be a relatively low level of flashing. 


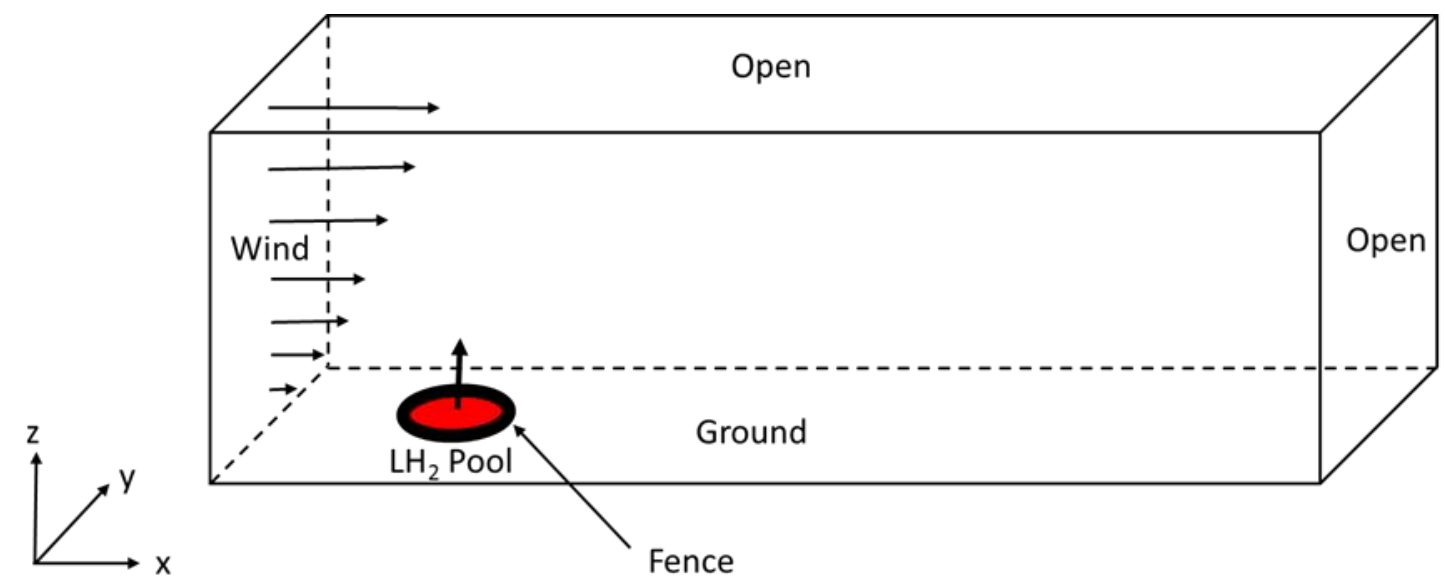

(a)

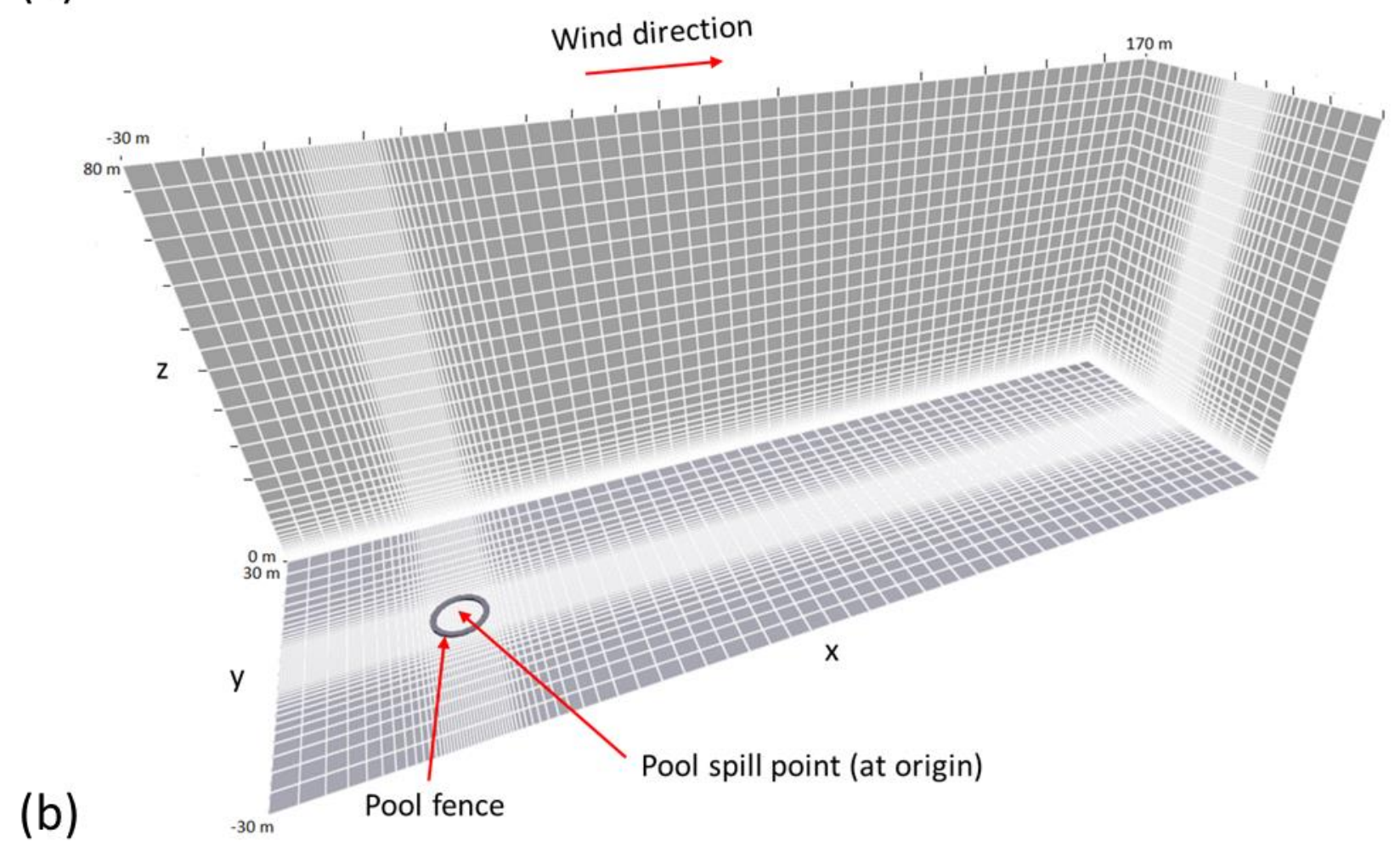

Fig. 1 - (a) Illustration of the boundary conditions used in the base-line simulations; (b) the grid and domain used in the base-line simulations.

\section{Results}

Model Comparison for NASA Test 6

Fig. 2 shows a comparison of the hydrogen concentrations observed experimentally with those predicted by the model at the four instrument tower sensor locations in NASA Test 6 , 
using both standard and hi-res grids and for wind directions (relative to the central axis of the instrumented towers) of $0^{\circ}$ and $24^{\circ}$.
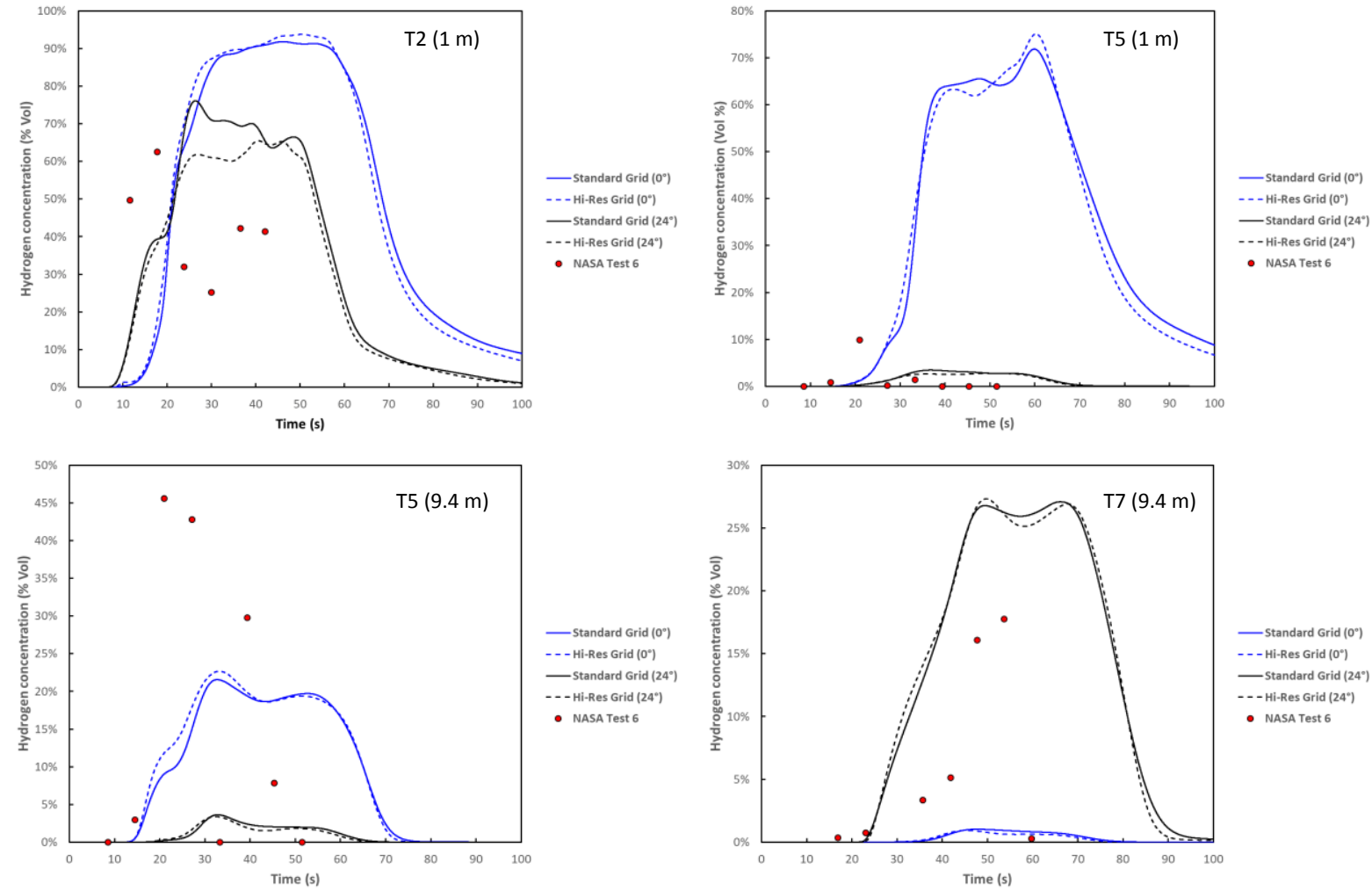

Fig. 2 - Comparison of hydrogen concentration results for NASA Test 6 with FLACS predictions standard and hi-res grids and for original sensor locations $\left(0^{\circ}\right)$ and rotated by an angle of $24^{\circ}$ to replicate a shift in mean wind direction: Tower 2 (height $1 \mathrm{~m}$ ); Tower 5 (height $1 \mathrm{~m}$ ); Tower 5 (height $9.4 \mathrm{~m}$ ) and Tower 7 (height $9.4 \mathrm{~m}$ ).

The results obtained for both the standard and hi-res grids are broadly consistent suggesting that a reasonable level of grid independence has been achieved using the standard grid, which was therefore adopted for use in this study. Using a wind direction of $0^{\circ}$, the model over-predicts the peak hydrogen concentrations observed at T2 $(1 \mathrm{~m})$ and T5 $(1 \mathrm{~m})$ and under-predicts those observed at T5 $(9.4 \mathrm{~m})$ and especially for T7 $(9.4 \mathrm{~m})$. By comparison, using a wind direction of $24^{\circ}$, a better level of agreement between the predicted and observed peak hydrogen concentrations is achieved at T2 $(1 \mathrm{~m})$ and T5 $(1 \mathrm{~m})$ and particularly for T7 (9.4 m), as the gas cloud now passes through this sensor location. However, the predicted peak hydrogen concentrations are very low at T5 (9.4), compared with those observed in the test, suggesting that the model is under-predicting the level of buoyancy of the gas cloud produced by the spill.

Fig. 3 shows a comparison of the hydrogen gas concentrations for the cloud along the centre-line, downwind of the spill point, observed experimentally in NASA test 6, around 20 seconds after the start of the spill [8], with those predicted by the FLACS pool model. It can be seen that the predicted cloud is reasonably similar in form to the experimental one, but that the experimental results suggest a greater level of upward dispersion and travel downwind. 


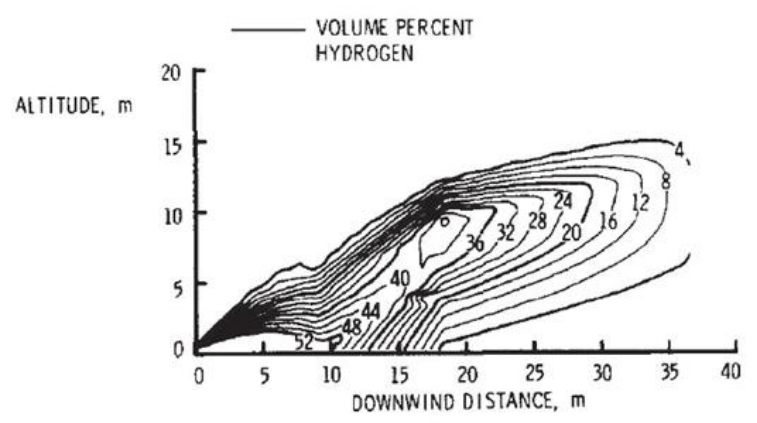

(a)

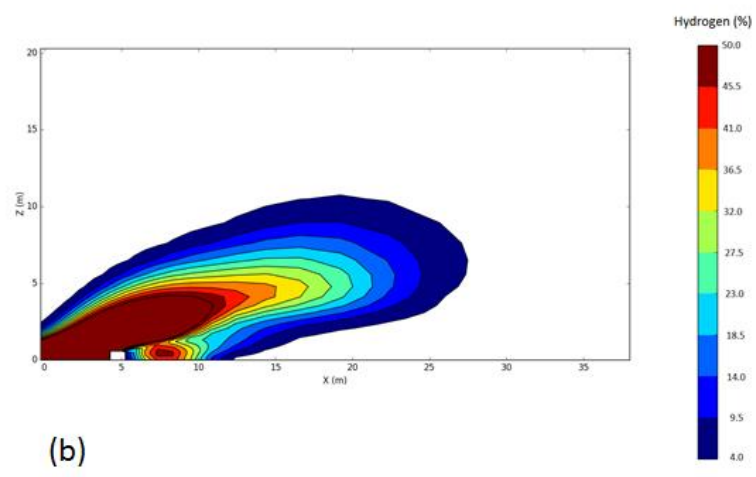

(b)

Fig. 3 - The hydrogen gas cloud concentration contours: (a) observed experimentally after $21.33 \mathrm{~s}$ [8]; (b) predicted by the FLACS pool model after $20 \mathrm{~s}$.

Fig. 4, shows the development of the flammable gas cloud predicted by the model for test 6 . The head of the flammable cloud rises upward whilst the body travels along the ground. Both downwind extent and the maximum height of the head of the flammable cloud increase with time as does the distance over which the cloud travels along the ground before starting to rise. The tail end of the cloud remains anchored to origin of the spill throughout the lifetime of the cloud. After the end of the release at $38 \mathrm{~s}$ the cloud continues to extend further downwind whilst gradually dispersing, to lower concentrations, and then below the flammable limit.

Fig. 5(a), show the radius of the LH2 pool versus time predicted by FLACS (for both standard and refined grids) compared with the experimental pool size range estimated for NASA test 6 and the predictions of another model - $\operatorname{LauV}[19,20]$. The FLACS pool results can be seen to be broadly consistent with those inferred from test 6 - predicting a slightly larger maximum pool radius and a very similar time to complete vaporization of the $\mathrm{LH} 2$ pool (around 45 seconds). The corresponding LH2 pool vaporisation rate predicted by FLACS is shown in Fig. 3(b). It initially peaks at a value of $0.11 \mathrm{~m}^{3} / \mathrm{s}$ before falling sharply and then gradually rising again in a fluctuating pattern approaching $0.1 \mathrm{~m}^{3} / \mathrm{s}$ before dropping to zero after 45 seconds. By contrast LAuV predicts a lower and a steadier maximum vaporisation rate of around $0.07 \mathrm{~m}^{3} / \mathrm{s}$. LAuV assumes that heat conduction from the ground is the dominant source of heat transfer for vaporization of a cryogenic pool and uses an expression similar in form to equation (16). The discrepancy of the LAuV results compared with the FLACS results (and also with NASA test results) may be at least partly attributable to differences in the heat transfer properties for the ground substrate (thermal conductivity and thermal diffusivity) that were assumed when modelling the NASA test. The FLACS results obtained for a concrete ground type (see below), suggest that the pool radius can be significantly larger if a lower value for thermal conductivity of the substrate is assumed. 

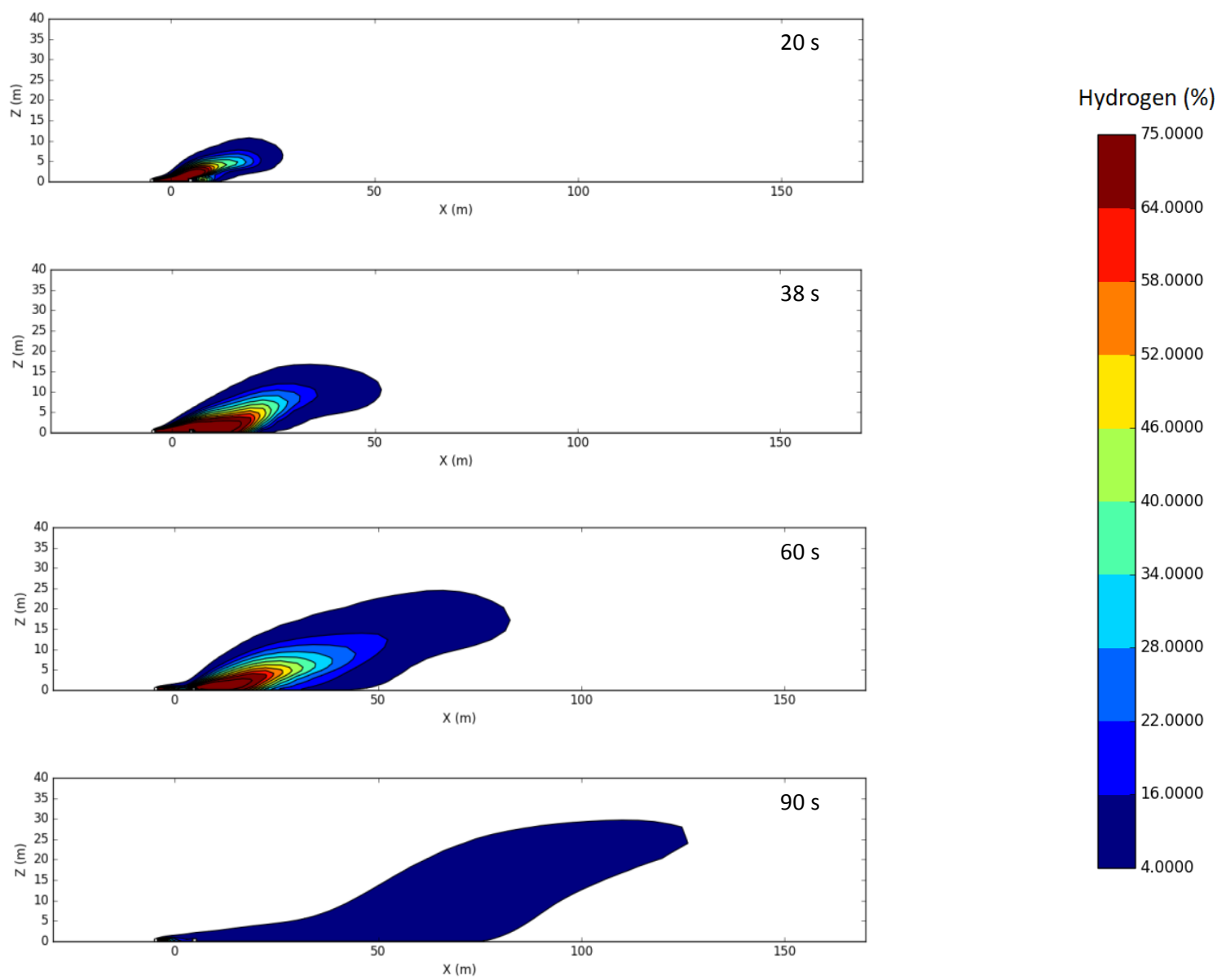

4.0000

Fig. 4 - Development of the predicted flammable hydrogen gas cloud with time after start of spill.

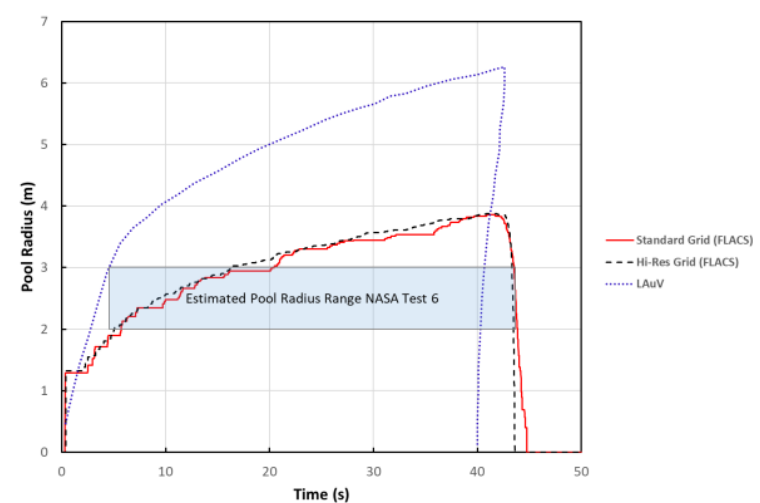

(a)

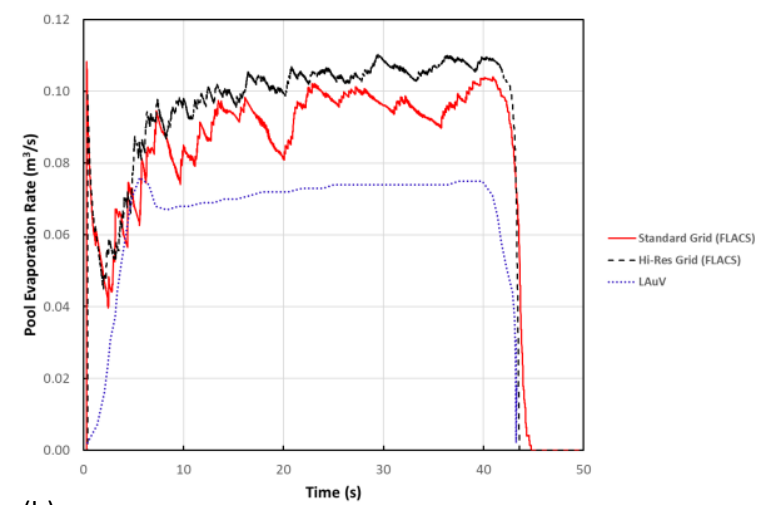

(b)

Fig. 5 - (a) Comparison of $\mathrm{LH} 2$ pool radius development with time (form start of spill) predicted by FLACS (using standard and hi-res grids) and LAuV with range estimated from NASA Test 6. (b) Comparison of pool evaporation rate variation with time predicted by FLACS and LAuV. 
The results of the NASA WSTF experiments reported in [9] provides details of the hydrogen gas clouds produced during the $\mathrm{LH} 2$ spill tests, including the maximum downwind distance of the cloud to the reach the LFL ( $4 \% \mathrm{v} / \mathrm{v}$ hydrogen in air), the maximum flammable height, time to total vaporisation of the LH2 pool and duration of the visible cloud (taken to indicate the approximate duration of the flammable cloud).

Table 1 presents a comparison between the observed and predicted results for three of the NASA tests. For the base-line Test 6 (release rate $9.5 \mathrm{~kg} / \mathrm{s}$, release duration $38 \mathrm{~s}$, wind speed $1.75 \mathrm{~m} / \mathrm{s}$ ) the predicted and observed maximum downwind flammable distances are the same, but the predicted flammable height is only half that found in the experiment. For Test 7 , where a slower release spill rate $(1.67 \mathrm{~kg} / \mathrm{s})$ was used over a long duration (120 s), at a higher mean wind speed $(4.16 \mathrm{~m} / \mathrm{s})$, both the downwind flammable distances are lower than those found for Test 6, but the observed distance is less than half the predicted one. On the other hand the flammable heights in this case are both relatively low suggesting that the gas cloud remains close to the ground. Finally, for Test 4, where a similar spill rate (10.3 $\mathrm{kg} / \mathrm{s}$ ) and duration ( $35 \mathrm{~s}$ ) to Test 6 was used, but the mean wind speed was almost double $(3.38 \mathrm{~m} / \mathrm{s})$, the downwind flammable distances are both higher than those found for Test 6 , although the predicted distance is about $30 \%$ greater than that observed. In this case the predicted flammable height is also less than half that found in the experiment. For tests where the data is available FLACS predicts very similar pool vaporisation times to those observed experimentally, but over predicts the duration of the visible cloud. The latter may be at least partially attributable to the difference between the visible cloud limit (at dew point - typically around $8 \% \mathrm{v} / \mathrm{v}[8]$ ) and LFL limits (4\% v/v).

Table 1 - Comparison between observed and predicted results for three NASA test conditions.

\begin{tabular}{|c|c|c|c|c|c|c|c|c|c|c|c|}
\hline \multirow[t]{2}{*}{ Trial } & \multirow[t]{2}{*}{$\begin{array}{l}\text { Release } \\
\text { Rate }(\mathrm{kg} / \mathrm{s})\end{array}$} & \multirow[t]{2}{*}{$\begin{array}{l}\text { Duration } \\
\text { (s) }\end{array}$} & \multirow{2}{*}{$\begin{array}{l}\text { Wind } \\
\text { Speed } \\
(\mathrm{m} / \mathrm{s})\end{array}$} & \multicolumn{2}{|c|}{$\begin{array}{l}\text { Max Flammable } \\
\text { Distance to LFL (m) }\end{array}$} & \multicolumn{2}{|c|}{$\begin{array}{l}\text { Max Flammable } \\
\text { Height }(\mathrm{m})\end{array}$} & \multicolumn{2}{|c|}{$\begin{array}{l}\text { Time to Total } \\
\text { Vaporization (s) }\end{array}$} & \multicolumn{2}{|c|}{$\begin{array}{l}\text { Visible Cloud } \\
\text { Duration (s) }\end{array}$} \\
\hline & & & & Expt. & FLACS & Expt. & FLACS & Expt. & FLACS & Expt. & FLACS \\
\hline 6 & 9.5 & 38 & 1.75 & 160 & 160 & 65 & 32 & 43 & 45 & 90 & 140 \\
\hline 7 & 1.67 & 120 & 4.16 & 61 & 144 & 9 & 7 & - & - & - & - \\
\hline 4 & 10.3 & 35 & 3.38 & 212 & 285 & 53 & 21 & 42 & 42 & 90 & 140 \\
\hline
\end{tabular}

The model reproduces similar qualitative trends with regard to the effect of spill rate, spill duration and wind speed on the flammable cloud behaviour to those observed in the experimental tests, although significant quantitative differences in the results are apparent. 

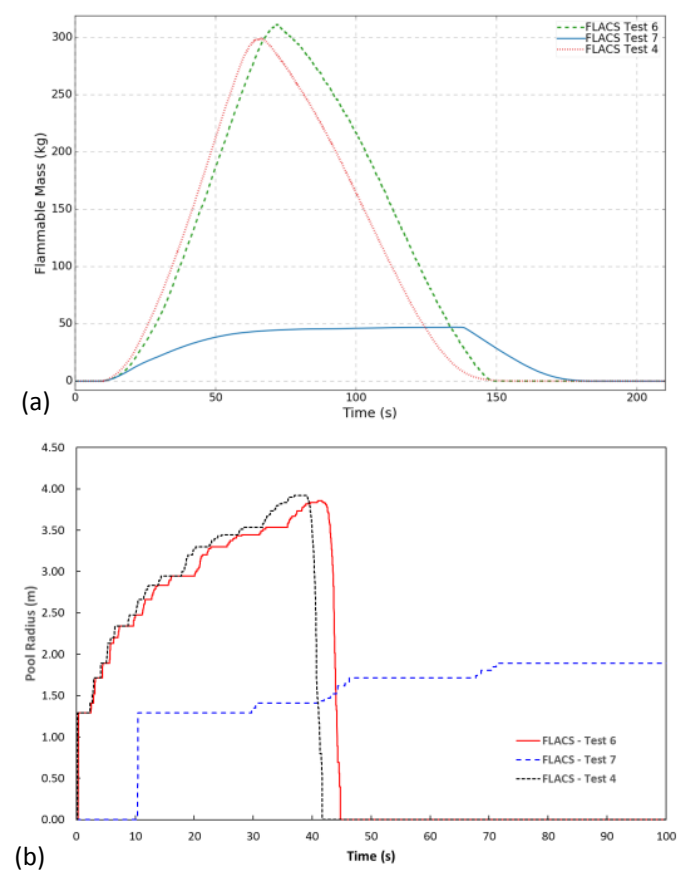

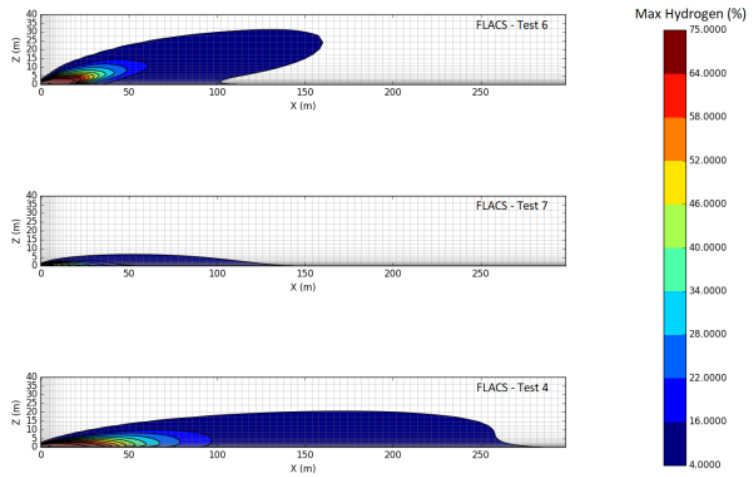

(c)

Fig. 6 - Comparison between FLACS results predicted for NASA test conditions 6, 7 and 4: (a) flammable mass of gas cloud versus time; (b) LH2 pool radius versus time; (c) Contour plot of maximum hydrogen concentration registered in each cell over the course of the simulation along the central $x-z$ plane.

Fig. 6 shows a comparison between the results predicted by FLACS for the three test conditions. Fig. 6(a) compares the predicted total mass of the flammable cloud versus time for the three tests. The curves predicted for Test 6 and Test 4 display a similar peak flammable mass and flammable time. In contrast, Test 7 exhibits a much lower maximum flammable mass and a longer flammable time. The results suggests that in this case the spill rate and duration (rather than wind speed) are the main factors determining the shape of the flammable mass curve.

Fig. 6(b) compares the predicted $\mathrm{LH} 2$ pool radius versus time for three tests. As with the flammable mass curves, the pool radius variation predicted for both Test 6 and Test 4 are very similar, where-as the curve for Test 7 displays a much slower rate of growth and reaches a maximum radius which is around half that found for the other two tests.

Fig. 6(c) compares the maximum concentrations for the flammable cloud along the central $\mathrm{X}-\mathrm{Z}$ plane predicted for three tests. Note that these contour plots show the maximum hydrogen concentration produced in a given control volume over the duration of the simulation. Hence, they do not show the hydrogen gas concentration at a particular instant of time, but instead provide a composite of the maximum values over time - indicating any location where the concentration has been greater than $4 \% \mathrm{v} / \mathrm{v}$. Hence, they demarcate the maximum flammable extent of the gas cloud over the course of the simulation. Compared to Test 6 , the cloud predicted for Test 7 is shorter and remains close to the ground. Conversely the predicted cloud for Test 4, has a much greater flammable extent than Test 6 . The results suggest that spill rate, duration and wind speed all play a role in determining the downwind flammable distance and height. 

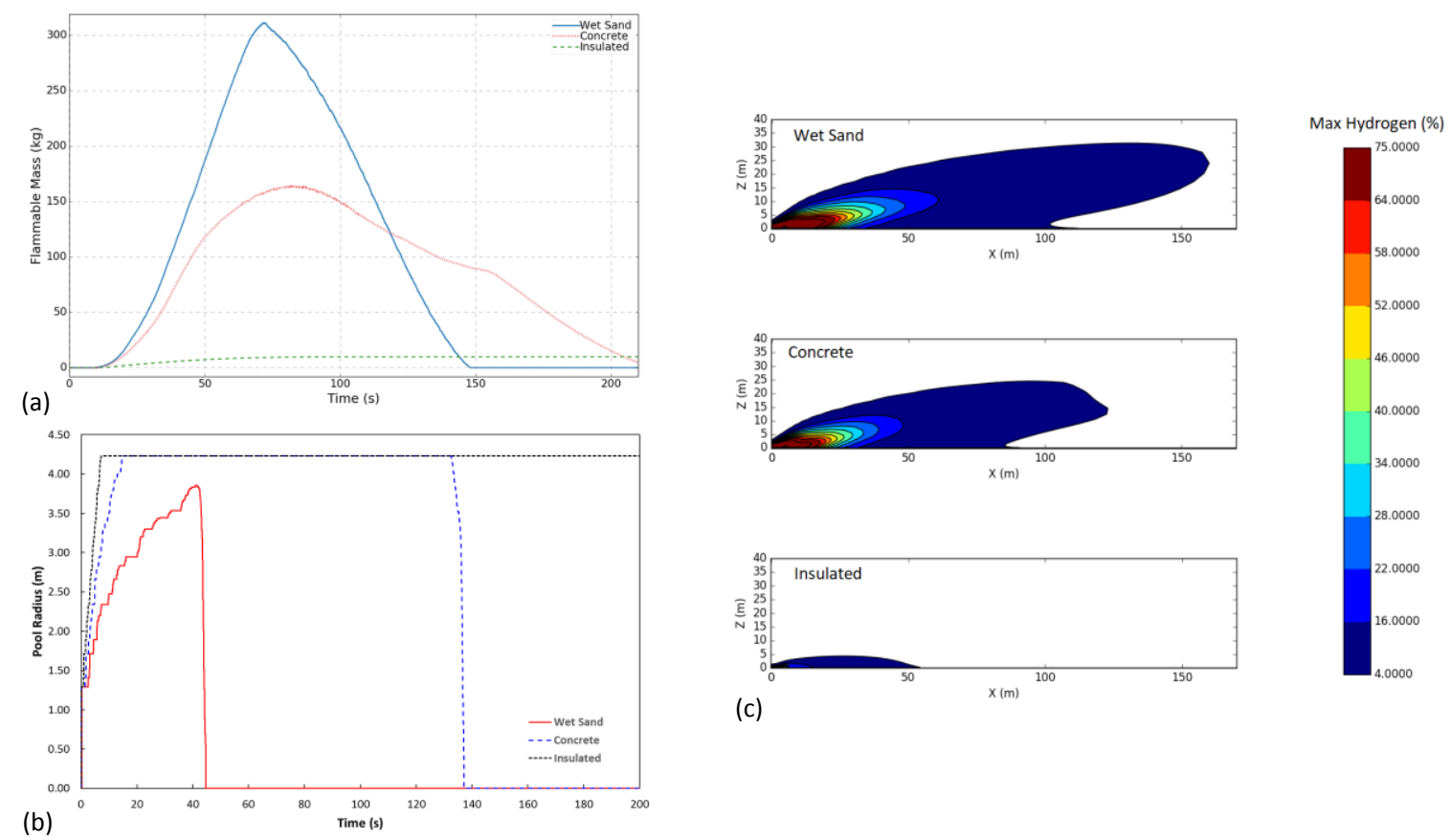

(c)

Fig. 7 - Effect of pool ground type on the predicted results for: (a) flammable mass versus time; (b) pool radius versus time; (c) maximum hydrogen concentration of flammable cloud.

\section{Effect of Pool Ground Type}

Fig. 7 shows a comparison between the flammable mass, flammable hydrogen cloud and LH2 pool size results predicted by FLACS for three different pool model ground types - wet coarse sand, concrete and insulated (characterised in terms of thermal conductivity and thermal diffusivity values given in Table 2 ). In each case the analysis has been performed for the Test 6 release scenario - but with an adjustment made to the ground substrate type.

Table 2. Pool model ground properties.

\begin{tabular}{lcc}
\hline Ground Type & Thermal Conductivity $(\mathrm{W} / \mathrm{m} / \mathbf{K})$ & Thermal Diffusivity $\left(\mathbf{m}^{2} / \mathbf{s}\right)$ \\
\hline & & \\
Wet coarse sand & 3.72 & $1.45 \times 10^{-6}$ \\
Concrete & 1.1 & $1.0 \times 10^{-6}$ \\
Insulated & 0.0 & $10^{30}$ \\
& & \\
\hline
\end{tabular}

Both concrete and particularly the wet coarse sand used for the Nasa Tests have a relatively high thermal inertia, meaning that the ground take longer to cool and so maintains greater temperature difference and rate of heat transfer to the LH2 pool. Hence the higher level of heat transfer from the concrete and particularly for the wet sand produces a much greater level of vaporisation of the $\mathrm{LH} 2$ pool (smaller maximum pool radius and shorter time to total vaporisation), cloud dispersion and greater peak flammable mass and flammable extent but for a shorter duration. In contrast for the insulated pool, there is no heat transfer from the ground to the pool - which rapidly grows to the maximum size of the pool, thereafter 
resulting in a slow steady vaporisation of the $\mathrm{LH} 2$ pool, and producing a sustained long duration flammable cloud with a relatively low flammable mass and a smaller flammable extent.

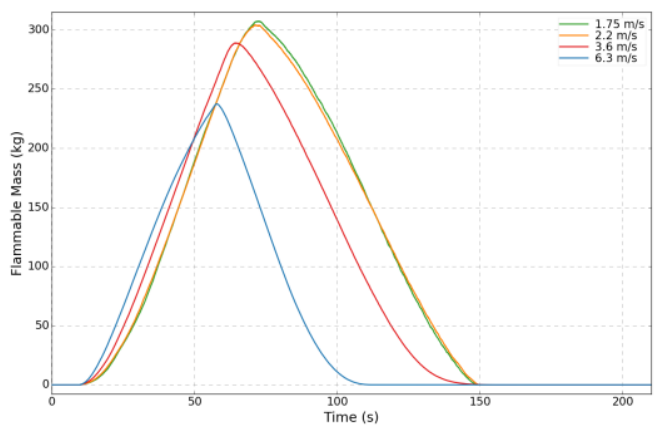

(a)

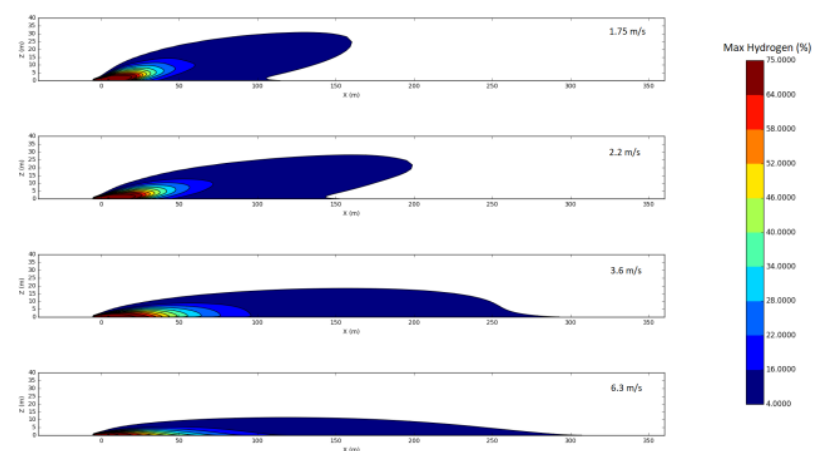

(b)

Fig. 8 - Effect of wind speed on the predicted results for: (a) flammable mass versus time; (b) maximum hydrogen concentration contour plots of the flammable cloud.

\section{Effect of wind speed}

Fig. 8 shows a comparison between the flammable mass and flammable hydrogen clouds predicted by FLACS for different wind speeds. At lower wind speeds the head of the cloud becomes buoyant rising away from the ground. At higher wind speeds the cloud becomes restricted to travelling along the ground, increasing the maximum downwind flammable distance and reducing the maximum flammable height reached. However, the level of dilution of the cloud also increases at higher wind speeds, with both the peak flammable mass and duration of the flammable cloud being reduced. This serves to limit the maximum flammable extent of the cloud. Thus, increasing the wind speed from $3.6 \mathrm{~m} / \mathrm{s}$ to $6.3 \mathrm{~m} / \mathrm{s}$ has only a small effect ( $5 \%$ difference) on the maximum downwind flammable distance reached by the cloud.

\section{Transient LH2 Spills}

A series of transient LH2 spills were simulated, using different release rates and spill durations, for a fixed total LH2 release mass of $1444 \mathrm{~kg}$ (without the spill pond fence). The conditions used for these simulations were the same as for the NASA Test 6 scenario: wet 
sand ground type, wind speed $1.75 \mathrm{~m} / \mathrm{s}$, and stability class F. Table 3 summarises the spill conditions simulated.

Table 3 - The transient LH2 spill conditions simulated for a fixed total LH2 mass of $1444 \mathrm{~kg}$

\begin{tabular}{ccc}
\hline Run & Leak Rate $(\mathbf{k g} / \mathbf{s})$ & Duration $(\mathbf{s})$ \\
\hline & & \\
T1 & 9.5 & 152 \\
T2 & 4.75 & 304 \\
T3 & 19 & 76 \\
T4 & 38 & 38 \\
T5 & 76 & 19 \\
\end{tabular}

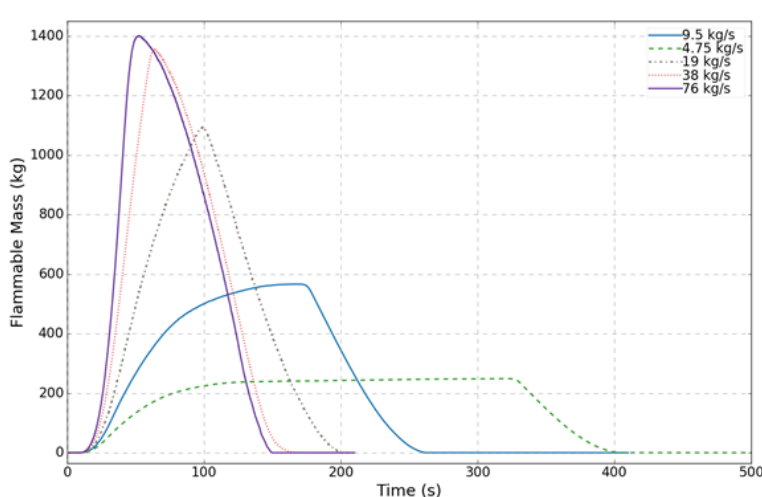

(a)

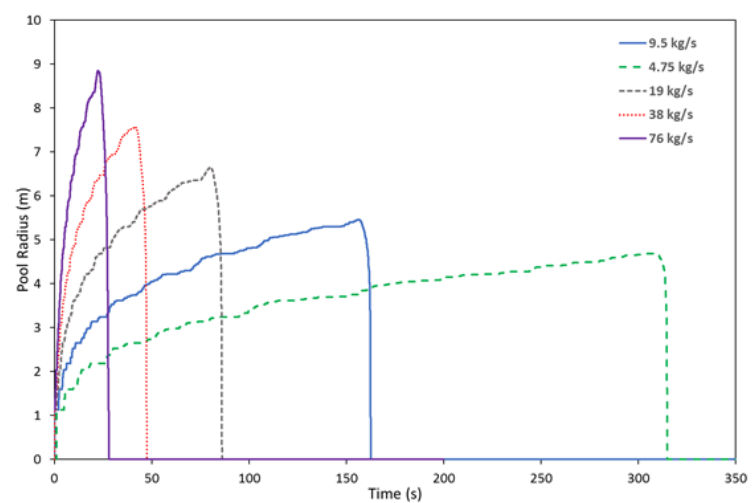

(b)

Fig. 9 - Comparison of predicted results varying the spill rate for a $1444 \mathrm{~kg}$ transient LH2 spill: (a) flammable mass versus time; (b) LH2 pool radius versus time. 


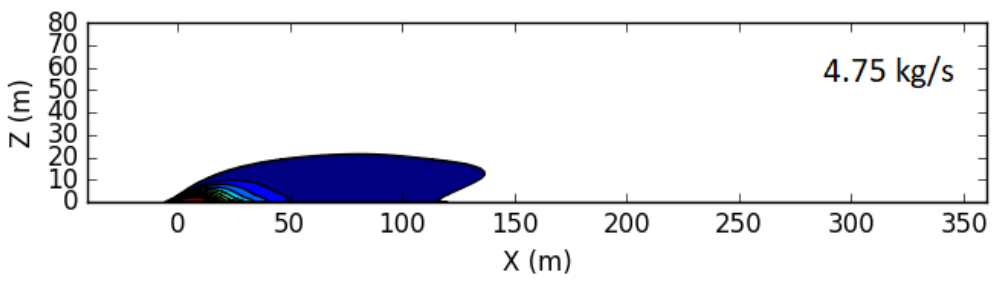

Max Hydrogen (\%)
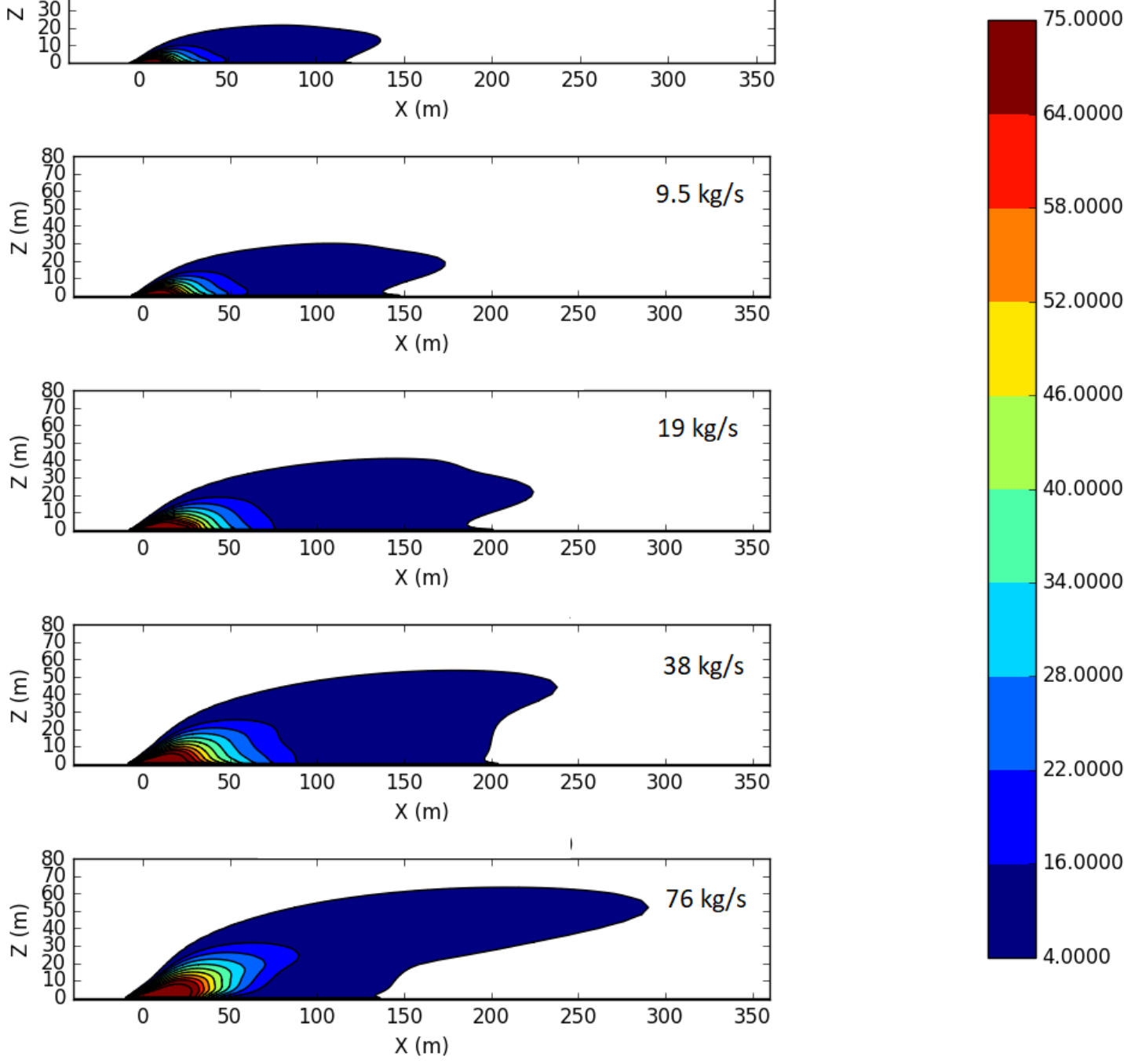

16.0000

Fig. 10 - Predicted maximum concentration contours for the flammable cloud along the central X-Z plane, at the different spills rates, for a $1444 \mathrm{~kg}$ transient release.

Fig. 9 shows a comparison between the results predicted by FLACS for the different transient spills examined. Fig. 9(a) compares the flammable mass of the gas cloud versus time. At the lowest spill rate, $4.75 \mathrm{~kg} / \mathrm{s}$, the flammable mass of the gas cloud formed is sustained at a relatively low level (around $250 \mathrm{~kg}$ ) over a long period of time. As the spill rate is increased the maximum flammable mass rises significantly, with the curve at higher spill rates tending towards a limiting form with a sharp peak (around $1400 \mathrm{~kg}$ ) for a shorter period of time.

The corresponding $\mathrm{LH} 2$ pool radius versus time curves, shown in Fig. 9 (b) follow a similar pattern. At the lower spill rates the resulting pool exhibits a slow steady growth over a long time period. Conversely, at higher spill rates the pool grows rapidly, becoming significantly larger, but with a much shorter total vaporisation time. 
Fig. 10 shows the variation in the predicted maximum concentration contours for the flammable cloud along the central X-Z plane, for the different spills. As the spill rate is raised the downwind extent of the flammable cloud increases as does the maximum height reached by the flammable cloud. At the highest spill rate, $76 \mathrm{~kg} / \mathrm{s}$, the distance travelled by the cloud before leaving the ground is also reduced relative to those predicted at some of the lower spill rates. The flammable extent of the cloud along the ground is governed by the interaction between the wind transporting the cloud along the ground and the vaporisation rate of the pool producing dispersion/mixing/buoyancy and upward transport of the cloud. It could be that, by producing a larger pool and greater vaporisation rate, the higher spill rate is enhancing the dispersion/mixing/buoyancy and consequently the upward movement of the gas cloud relative to downwind transport along the ground by the wind, thus causing the cloud to rise more readily and reducing the flammable extent of the cloud along the ground.
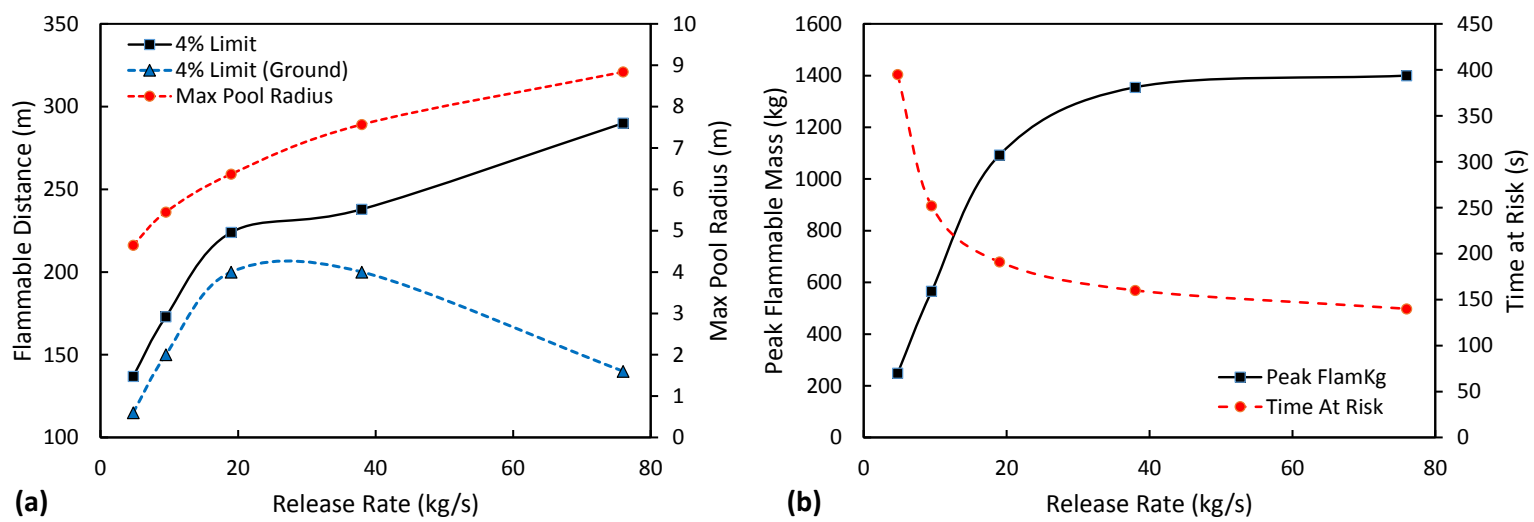

Fig. 11 - Predicted variation with release rate for transient $1444 \mathrm{~kg}$ spill of: (a) flammable distance of $4 \%$ Limit and maximum radius of LH2 pool; (b) Peak flammable mass of gas cloud and time period over which gas cloud is flammable (time-at-risk).

Fig. 11(a) shows the effect of the spill rate on both the maximum downwind flammable distance reached by the cloud (for any height and also just at ground level) and the maximum radius of the $\mathrm{LH} 2$ pool formed. Both the predicted maximum flammable distance at any height and the pool radius respectively increased from $137 \mathrm{~m}$ and $4.65 \mathrm{~m}$ at $4.76 \mathrm{~kg} / \mathrm{s}$ to $290 \mathrm{~m}$ and $8.84 \mathrm{~m}$ at $76 \mathrm{~kg} / \mathrm{s}$. However, it can also be seen that, in contrast to the maximum flammable distance at any height, the maximum flammable distance reached at ground level does not continue to rise as the release rate is increased, but instead falls back for release rates above $38 \mathrm{~kg} / \mathrm{s}$. Hence the results suggest that, in terms of the flammable extent of the cloud produced at ground level, the level of hazard for higher spill rates may be reduced (for the specific wind conditions and ground type examined). Fig. 11(b) shows the variation of both the peak flammable mass and the time-at-risk over which the gas cloud is flammable, with the release rate of the transient spill. As the spill release rate is increased the flammable cloud mass rises steeply before approaching a limiting value of around 1400 $\mathrm{kg}$. Conversely the time-at-risk of the flammable cloud is reduced significantly to around 140 s. 


\section{Continuous Spills (600 seconds)}

To examine the relationship between maximum downwind hazardous distance (and LH2 pool radius) and spill release rate for continuous spills, a series of simulations were performed at different steady LH2 spill release rates (between 0.1 and $20 \mathrm{~kg} / \mathrm{s}$ ) using a fixed spill duration of 600 seconds (to approximate the results found under continuous release steady state conditions).

The model parameters adopted in these FLACS simulations were based upon those recommended for use in the dispersion modelling of LNG designs spills [39-40] where the maximum duration of the release is set to 10 minutes (600 seconds) intended to represent worst case dispersion conditions (at least for LNG clouds):

- Atmospheric stability Pasquill-Gifford Class F

- Wind speed $2.0 \mathrm{~m} / \mathrm{s}$ measured at $10 \mathrm{~m}$

- Surface roughness of $0.03 \mathrm{~m}$

- Concrete pool substrate

\section{Relationship between flammable distance and release rate}

As well as the $4 \% \mathrm{v} / \mathrm{v}$ lower flammability limit for hydrogen, the $8 \% \mathrm{v} / \mathrm{v}$ hydrogen (limit for downward flame propagation) and $18 \% \mathrm{v} / \mathrm{v}$ hydrogen (limit for $\mathrm{H}_{2}$-air detonation) and a gas cloud temperature of $200 \mathrm{~K}$ (temperature threshold taken for cryogenic injury to occur) were also used as criteria to set the location of the maximum downwind hazardous distance.

Fig. 12 shows the maximum downwind hazardous distances (at ground level) predicted by FLACS for the gas cloud as a function of the LH2 spill release rate, using the $4 \%, 8 \%$ and $18 \%$ $\mathrm{v} / \mathrm{v}$ hydrogen-air concentration limits, and the $200 \mathrm{~K}$ cryogenic temperature limit (taken as the temperature threshold for cryogenic injury [40]). In all cases the hazardous distance exhibits an approximately power law relationship with the LH2 spill release rate. The $4 \% \mathrm{LFL}$ criteria sets the longest (most conservative) hazardous distance, whilst the hazardous distance of the cloud from the spill to the $200 \mathrm{~K}$ temperature threshold for cryogenic injury is significantly shorter. 


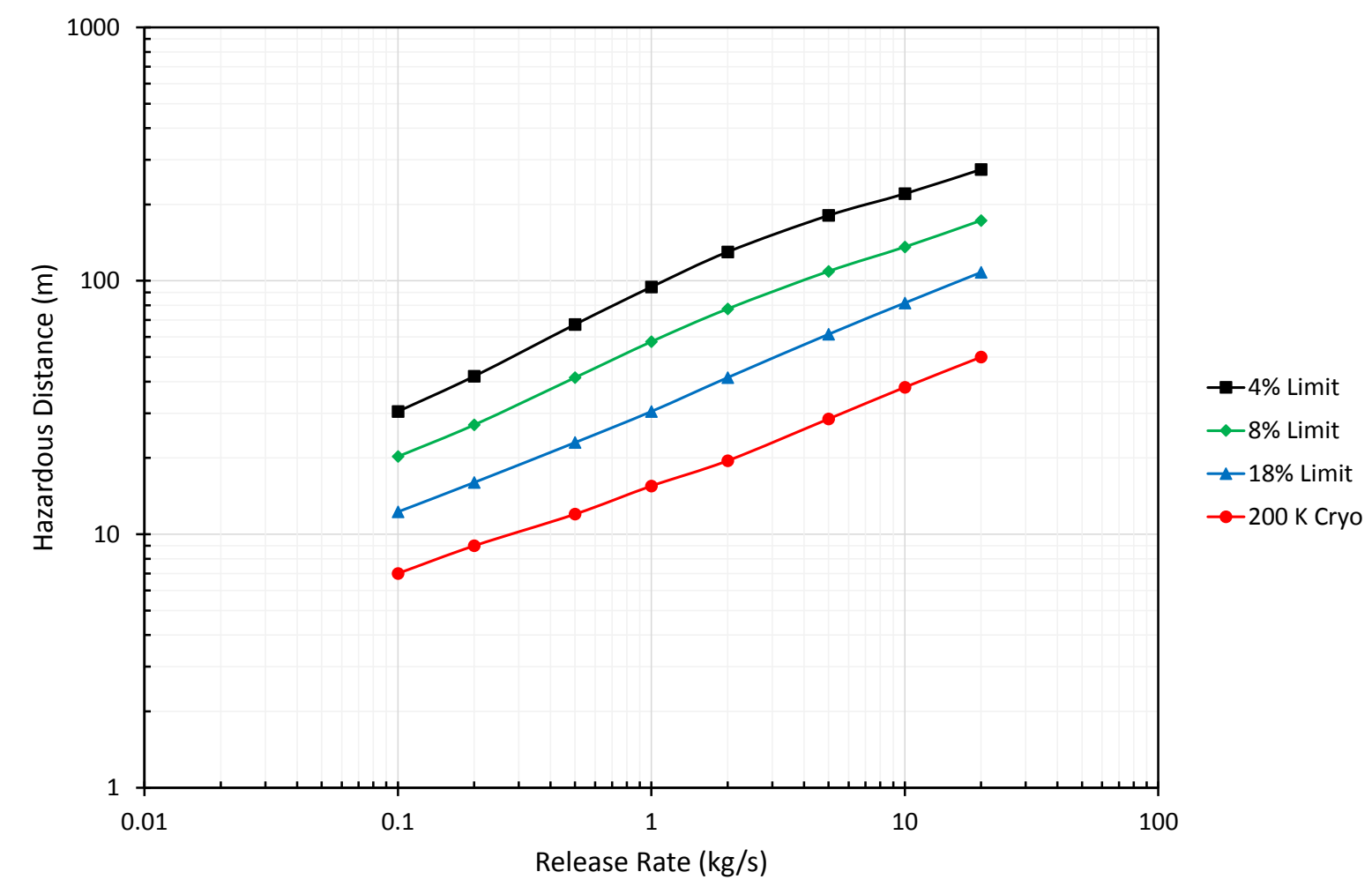

Fig. 12 - The maximum downwind hazardous distances predicted by FLACS for $4 \%, 8 \%$ and $18 \%$ hydrogen concentration limits and $200 \mathrm{~K}$ temperature limit as a function of the release rate for a continuous $600 \mathrm{~s}$ spill.

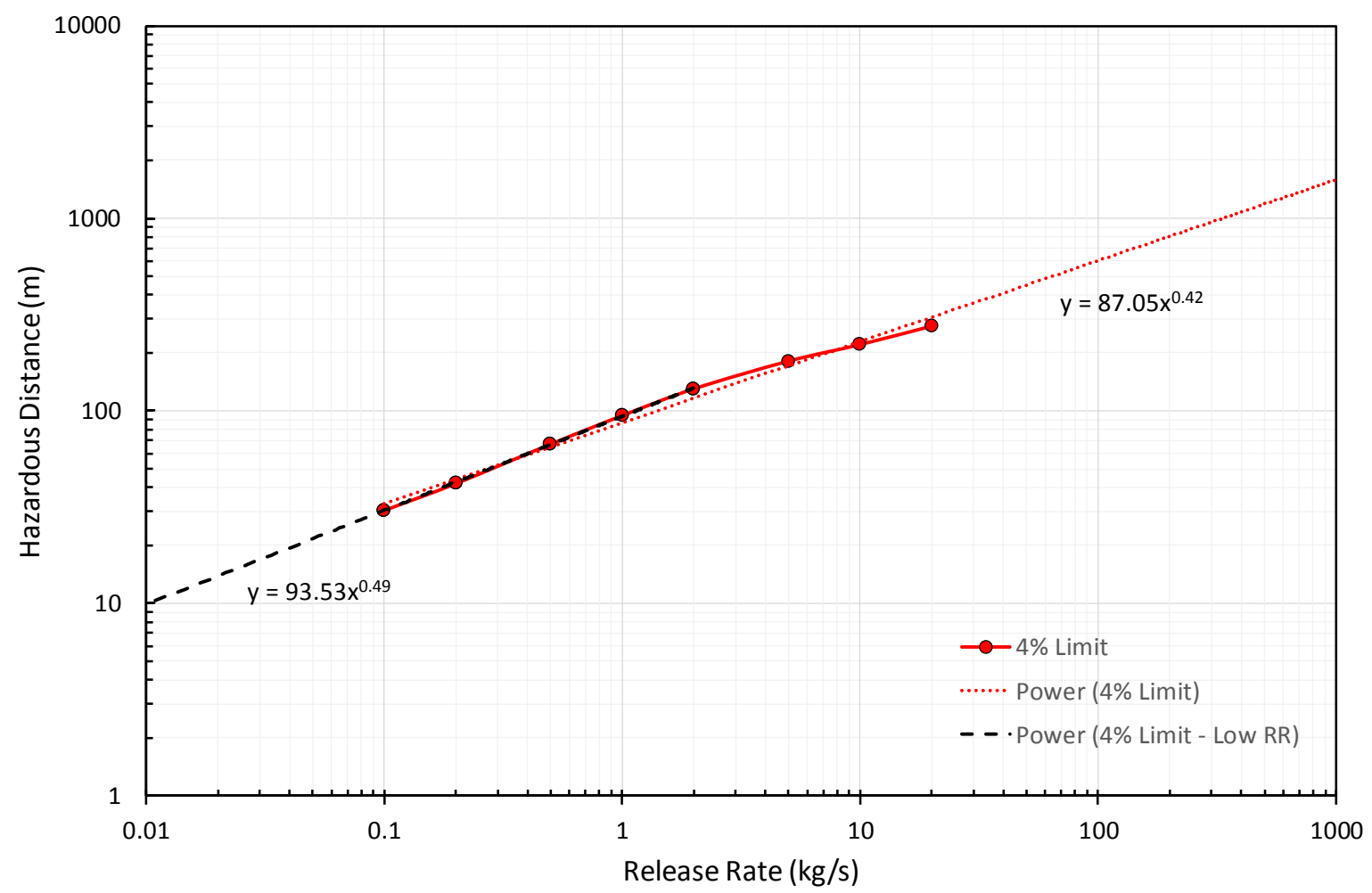

Fig. 13 Power law correlations fitted to the $4 \%$ hazardous distance limit data. 
In order to obtain a correlation that could be used to estimate the hazardous distance (at ground level) for a given $\mathrm{LH} 2$ release spill rate a power law relationship was fitted to the FLACS 4\% limit data (see Fig. 13). Two correlations were obtained. The first fit was performed across the entire FLACS $4 \%$ limit data set:

$x_{H}=87.05\left(F_{\text {dis }}\right)^{0.42}$

Where $x_{H}$ is the hazardous distance to the $4 \%$ limit $(\mathrm{m})$ and $F_{\text {dis }}$ is the discharge rate of the spill $(\mathrm{kg} / \mathrm{s})$.

However, it is also apparent from the FLACS $4 \%$ limit data, that at higher release rates the points are tending to curve downwards, below the fitted linear relationship (on a log-log plot) than may be projected from the points at lower release rates. This may reflect the effect of the flammable cloud lifting away from ground level, after a certain distance, at higher release rates (as was observed for the transient spills - see Fig 10.) , thus reducing the hazardous extent of the cloud at ground level. In contrast to the transient spills, where the hazardous distance at ground level was found to decrease at the highest spill rate, the hazardous distance found for the continuous spills, shown in Figs. 12 and 13, continues to increase across the range of spill rates considered. However, the downward curvature of the line indicates that it might exhibit a similar trend at high enough spill rates. This suggests that the extrapolated correlation for hazardous distance (at ground level) may be conservative at higher spill rates (but possibly excessively so).

A second fit was also performed to the FLACS results obtained at lower release rates, to try to give an estimate of the hazardous distance behaviour for low release rates:

$x_{H}=93.53\left(F_{\text {dis }}\right)^{0.49}$

Note that Eq. 29 is based on an extrapolated fit to five data points - so can only be regarded as being indicative.

The correlations could also be used to estimate the hazardous distance for $\mathrm{LH} 2$ release rates, outside the range of those simulated. However, such extrapolated results should obviously be treated with caution as the physical behaviour of the system may change at different scales. It should also be kept in mind that this correlation has been derived from modelling results obtained for a specific ground type (concrete) and reference wind speed $(2 \mathrm{~m} / \mathrm{s})$. A different wind speed or pool ground type might produce a different correlation. Hence, they should be used with caution. 


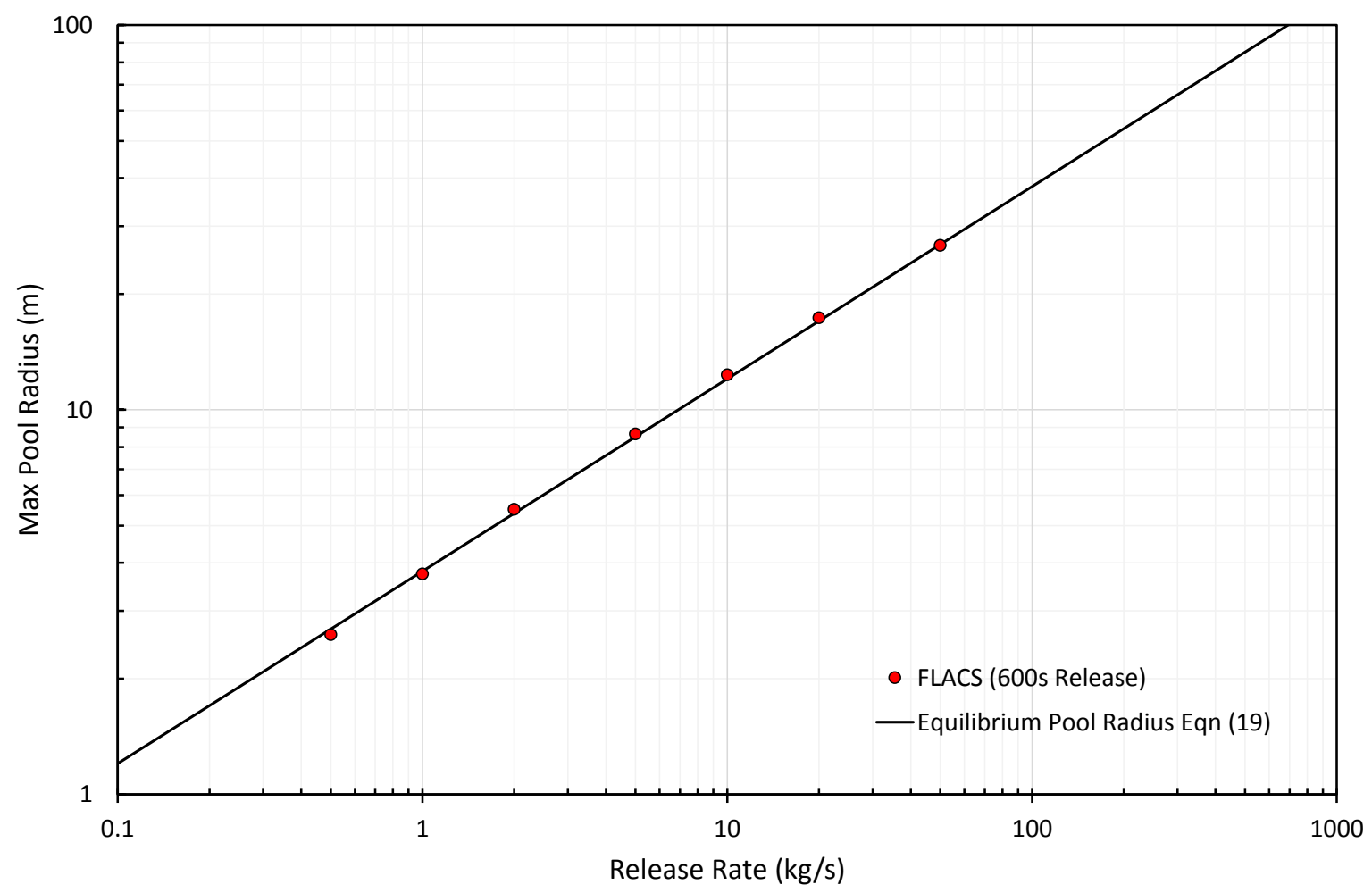

Fig. 14 - Equation for equilibrium pool radius equation fitted to FLACS results.

\section{Maximum Pool Radius versus Release Rate}

For a continuous LH2 spill release rate, maintained over a sufficiently long time, the size of the pool formed should eventually reach a steady-state equilibrium (when the evaporation rate from the pool equals the discharge rate into the pool). Woodward \& Pitblado ([40] pg. 137) give an expression for the equilibrium pool radius, $R_{e q}(\mathrm{~m})$, of an LNG pool (which should also be valid for $\mathrm{LH}_{2}$ spills) as:

$R_{e q}=\left(\frac{F_{\text {dis }}}{\pi G_{\text {evap }}}\right)^{1 / 2}$

where $G_{\text {evap }}$ is the steady-state evaporation rate of the pool per unit area $\left(\mathrm{kg} / \mathrm{m}^{2} / \mathrm{s}\right)$.

Fitting the equation for $R_{e q}$ to the FLACS $600 \mathrm{~s}$ simulation results, for the maximum pool radius predicted at different LH2 spill release rates, the FLACS results can be seen to be in excellent agreement with Eqn. 30, as shown in Fig. 14. Based upon this fit, the value of $G_{\text {evap }}$ is estimated to be $0.022 \mathrm{~kg} / \mathrm{m}^{2} / \mathrm{s}$ for the concrete ground type used. However, this value is between $15-25 \%$ higher than the corresponding pool evaporation rates per unit area estimated directly from the FLACS pool model simulations. The reason for this is that, even after $600 \mathrm{~s}$, the pool still hasn't reached a steady-state condition, and the spill rate into the pool remains in excess of the evaporation rate from the pool. 


\section{Discussion}

Possible explanations for under-predicting gas cloud dispersion

In section 5 a comparison of the experimental results for NASA Test 6 with those predicted by the model suggested that the FLACS pool model is under-predicting the level of gas cloud dispersion. Possible explanations for the enhanced levels of dispersion observed in the experimental test are:

i. Variable wind speed and direction - The model is only using a mean wind velocity and direction - but significant variations in both wind speed and direction were observed to occur during the course of the experimental test. Such wind fluctuations would enhance dispersion of the gas cloud.

ii. Turbulence generated by $\mathrm{LH} 2$ spill - it was observed in the experimental tests that significant turbulence was generated at higher spill rates, via the momentum of spill and the violent boiling and vaporisation of the liquid hydrogen pool formed, promoting higher levels of dispersion of the hydrogen gas cloud.

iii. Neglecting flash vaporisation - A significant fraction of the LH2 (which was released under pressure) may have undergone flash vaporisation during transport and release in NASA Test 6 . This flash vaporised vapour release could have produced enhanced dispersion levels.

iv. Neglecting effect of condensed water vapour, oxygen and nitrogen from the atmosphere. The gas cloud formed by the vaporising LH2 is extremely cold (2OK) upon release, causing water vapour in the atmosphere to condense into water vapour (at its dew point) when in come into contact with hydrogen cloud. The latent heat released during phase change from gas vapour to liquid, will heat the hydrogen gas cloud, increasing its temperature and reducing it density - hence enhancing its buoyancy and level of dispersion. See for example $[15,41]$.

v. The FLACS pool model does not include direct heating of the gas cloud by the ground - outside of the LH2 pool region - which might be expected to increase the buoyancy of the cloud in contact with ground and hence reduce the hazardous distance of the cloud along the ground.

\section{Comparisons with EN 60079-10-1}

As part of the standard (BS) EN 60079-10-1 (IEC 60079-10-1) [42], concerned with classifying areas where flammable gas or vapour hazards may arise, a method for estimating the extent of a hazardous zone formed by the release of a flammable substance, including from an evaporative pool formed from a gas liquefied by refrigeration, such as LH2, is given. In this method the hazardous distance is expressed in the form of a chart and expressed as a function of the release characteristic $\left(\mathrm{m}^{3} / \mathrm{s}\right)$, given by: 
$\frac{W_{g}}{\left(\rho_{g} \times k \times L F L\right)}$

Where $W_{g}$ is the gaseous mass release rate (evaporation rate) of flammable substance $(\mathrm{kg} / \mathrm{s}), \rho_{g}$ is the density of the gas formed $\left(\mathrm{kg} / \mathrm{m}^{3}\right), k$ is a safety factor associated with the $\mathrm{LFL}$, typically between 0.5 and 1 , and LFL is the lower flammability limit for the gas release (0.04 v/v for hydrogen).

Fig. 15 compares the maximum downwind hazardous distance predicted by FLACS for the 4\% limit with the curve given in (BS) EN 60079-10-1 ([42] Annex D - Figure D.1) for a heavy gas release (note that this curve been extrapolated - broken line - to match the release characteristic range covered the FLACS results). Two limit lines are shown for the FLACS results. The first of these ("FLACS - Spill Rate") calculates the release characteristic by assuming that the rate of evaporation from the pool is equal to the spill rate as would occur under steady-state conditions. The second line ("FLACS - Evap Rate") calculates the release characteristic using the pool mass evaporation rate calculated by FLACS after $600 \mathrm{~s}$. It can be seen that the "FLACS - Evap Rate" line lies slightly above the "FLACS - Spill Rate" line indicating a larger hazardous distance (by around $10 \mathrm{~m}$ ) for a given release characteristic value.

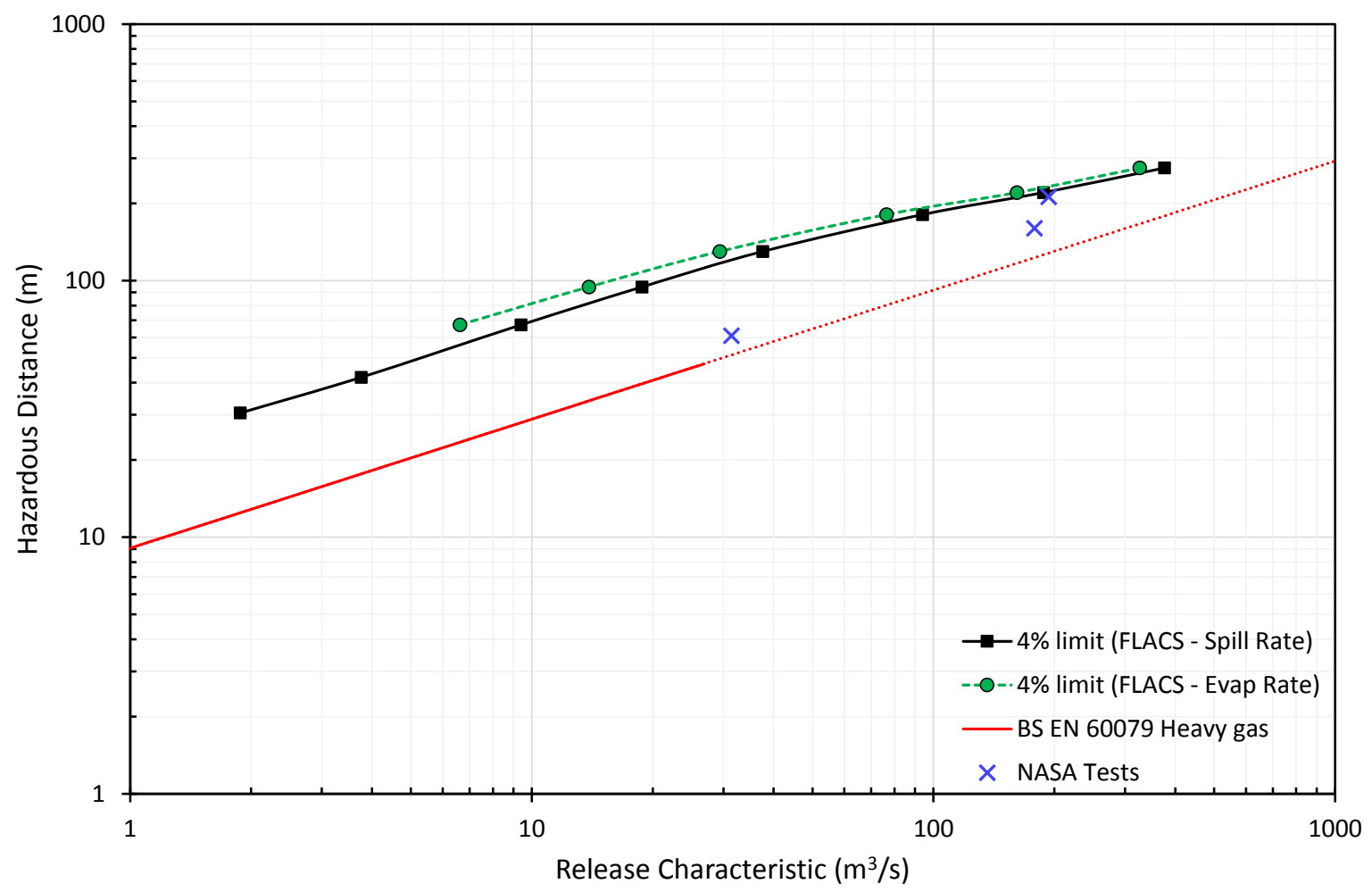

Fig. 15 - Comparison of $4 \%$ flammable limit hazardous distance versus release characteristic predicted by FLACS with the (extrapolated curve) given in EN 60079 for a heavy gas.

At lower release rates the FLACS predictions for the 4\% LFL hazardous distance of the cloud appear to follow a similar power law scaling relationship (i.e. similar gradient) with release characteristic to the EN 60079 heavy gas curve. However, the FLACS hazardous distances are somewhat more conservative than those suggested by EN 60079, by a factor of approximately two. The downwind flammable distances estimated from the size of the 
visible cloud for some of the NASA WSTF tests are also shown - to provide a comparison with experiment. The hazardous distance for the lower release rate test lies closer to the EN 60079 line, but for the higher release rate tests the hazardous distance is significantly higher than the limit predicted by EN 60079, and closer to the limit predicted by FLACS.

Note that the release characteristic calculated for these tests assumes that the evaporation rate from the $\mathrm{LH} 2$ pool is equal to the release spill rate, which may not be appropriate for these transient releases. If the pool evaporation rate is less than spill rate, as would be the case for a growing pool, then the release characteristic for the tests would shift to lower values, increasing the distances above the EN 60079 line and improving the match with the limit predicted by FLACS. Since the flammable distances for the tests are estimated from the size of the visible (water vapour) cloud they may also underestimate the location of the $4 \%$ hydrogen-air flammability limit. Hence, comparison with the limited experimental test data available suggests that the more conservative hazardous distances predicted by FLACS for LH2 pool spills may be plausible.

It is possible that the greater hazardous distances predicted by FLACS in comparison to the heavy gas curve given in EN 60079-10-1 may reflect limitations in the modelling approach employed in the FLACS pool model (e.g. neglecting the effect of heat transfer to the cloud from the ground outside the pool region). However, in a recent research paper Hansen [30] has shown that liquid hydrogen releases do indeed exhibit dense gas behaviour and found that the hazardous distance for an LH2 release can be significantly longer than for other gases exhibiting dense gas behaviour, such as LNG. Hence, it may be that the heavy gas curve given in EN 60079, whilst applicable to other heavy gases, is under-predicting the true hazardous distance when applied to the case of a $\mathrm{LH} 2$ release.

Few details of the methodology used to obtain the heavy gas curve chart presented in Figure D.1 in BS EN 60079-10-1 are given in [42], beyond that it is based upon the continuity equation and selected CFD simulations, assuming a dispersion distance proportional to the square root of the $\mathrm{X}$ axis and also noting that the results have been moderated for the purpose of the standard. Hence, it is difficult to determine the limitations of the methodology applied in EN 600079 to predicting the hazardous behaviour of dense gases in comparison to that used by FLACS, or whether those predictions could be expected to apply in the case of $\mathrm{LH} 2$.

Finally, although the hazardous distance predicted for large scale LH2 pool spills are significant it should also be kept in mind that such releases are expected to be rare events. If the regulations and standards for LH2 safety are not to be overly onerous, it has been recommended in NFPA-2 that a risk informed approach to safety assessments should be adopted [43]. Hence, both the consequences and the frequency of occurrence of a LH2 spill scenario should be taken into account when assessing the overall level of risk.

\section{Conclusion}

The FLACS CFD model has been used to simulate large scale LH2 pool releases to examine their behaviour and predict the LH2 pool size, downwind hazardous distance, and 
flammable mass of the hydrogen-air clouds formed for different environmental conditions and release scenarios.

Comparisons with large-scale NASA LH2 spill data for test 6 suggests that the FLACS pool model is under-predicting the level of dispersion of the gas cloud produced by the LH2 spill. This may be attributed to: (i) variations in both the wind speed and direction occurring during the course of the experimental test; (ii) enhanced levels of turbulence generated by the LH2 spill observed in the tests; and (iii) the model neglecting the effect of condensed water vapour, oxygen and nitrogen from the air. The FLACS model predictions of LH2 pool size are consistent with those observed in the test.

A comparison between the observed and predicted behaviour of the flammable gas cloud, including the maximum downwind distance of the cloud to the reach the $L F L$, the maximum flammable height, time to total vaporisation of the LH2 pool and duration of the visible cloud was made for three of the NASA tests. The FLACS model reproduces similar qualitative trends with regard to the effect of spill rate, spill duration and wind speed on the flammable cloud behaviour to those observed in the experimental tests, although significant quantitative differences in the results are also apparent. The results also suggest that spill rate, duration and wind speed all play a role in determining the downwind flammable distance and height of the cloud, but that spill rate and duration (rather than wind speed) are the main factors determining the shape of the flammable mass curve.

Using the model to examine the effect of different pool ground types, materials with a higher thermal conductivity (e.g. wet sand) were found to produce a cloud with a greater peak flammable mass and flammable extent, but for a shorter duration.

At lower wind speeds the head of the cloud becomes buoyant rising away from the ground, while at higher wind speeds the cloud becomes restricted to travelling along the ground, increasing the downwind flammable distance. However, the level of dilution of the cloud also increases with wind speed, serving to limit the maximum flammable extent reached by the cloud.

A series of transient LH2 spills were simulated, using different release rates and spill durations, for a fixed total $\mathrm{LH} 2$ release mass of $1444 \mathrm{~kg}$ (without the spill pond fence). At higher spill rates the downwind extent of the flammable cloud increases as does the maximum height reached by the flammable cloud. The distance travelled by the cloud before leaving the ground is also reduced.

FLACS simulations were also performed at a number of different continuous LH2 spill release rates (between 0.1 and $20 \mathrm{~kg} / \mathrm{s}$ ) using a fixed spill duration of 600 seconds to try to approximate the results found under steady state conditions.

The FLACS pool model was used to predict the maximum downwind hazardous distances as a function of the LH2 spill release rate for the $4 \%, 8 \%$ and $18 \% \mathrm{v} / \mathrm{v}$ hydrogen-air concentration limits, and the $200 \mathrm{~K}$ cryogenic temperature limit and were found to exhibit a power law relationship. 
Correlations were obtained using the FLACS $4 \%$ limit data allowing the hazardous distance for a given $\mathrm{LH} 2$ release spill rate to be estimated.

The dependence of the maximum pool radius upon $\mathrm{LH} 2$ release rate predicted by FLACS for the $600 \mathrm{~s}$ simulations was also examined and found to be in excellent agreement with an analytical expression for the equilibrium pool radius, with the steady-state evaporation rate of the LH2 pool per unit area estimated to be $0.022 \mathrm{~kg} / \mathrm{m}^{2} / \mathrm{s}$ for a concrete type ground.

Finally, the maximum downwind flammable distances predicted by FLACS for the $4 \%$ limit were compared with the method for estimating hazardous distance of a release given in BS EN 60079-10-1 (Annex D - Figure D.1) for a heavy gas release. The hazardous distances found using FLACS are somewhat more conservative than those suggested by BS EN 60079, by a factor of approximately two. Comparison with the limited experimental test data available suggests that the more conservative hazardous distances predicted by FLACS for LH2 pool spills may be plausible.

\section{References}

[1] Klebanoff LE, Pratt JW, LaFleur CB. Comparison of the safety-related physical and combustion properties of liquid hydrogen and liquid natural gas in the context of the SF-BREEZE high-speed fuel-cell ferry, Int J Hydrogen Energy 2017; 42(1):757-74.

[2] https://www.nasa.gov/topics/technology/hydrogen/hydrogen fuel of choice.html (accessed 06.02.2020)

[3] https://www.enableh2.eu/ (accessed 06.02.2020).

[4] https://phys.org/news/2019-05-nasa-funds-aviation-fuel-concept.html (accessed 06.02.2020).

[5] https://www.sintef.no/globalassets/sintef-industri/arrangement/hydrogen-safety2019/11 large-scale-lh2-supply-chain-project--h2-gas-turbinedemonstration $\mathrm{k}$ morimoto kawasaki hi.pdf (accessed 06.02.2020)

[6] https://www.gasworld.com/nasa-to-build-worlds-largest-h2-tank/2016328.article (accessed 06.02.2020)

[7] Arthur D. Little, Inc. Final report on an investigation of hazards associated with the storage and handling of liquid hydrogen. Report to the U.S. Air Force, C-61092. 1960.

[8] Witcofski, R D, Chirivella, JE. Experimental and analytical analyses of the mechanisms governing the dispersion of flammable clouds formed by liquid hydrogen spills, Int J Hydrogen Energy 1984; 9(5):425-35.

[9] Chirivella JE, Witcofski RD. Experimental results from fast 1500 gallon LH2 spills. Cryog Prop Process Appl, AIChE Symp Ser, 1986; 251(82):120-40.

[10] Statharas JC, Venetsanos AG, Bartzis JG, Wurtz J, Schmidtchen U. Analysis of data from spilling experiments performed with liquid hydrogen. J Hazard Mater 2000; 7: 57-75.

[11] Royle M, Willoughby D. Releases of unignited liquid hydrogen, Health and Safety Laboratory, HSE Report, RR986, 2014.

[12] Middha P, Ichard M, Arntzen BJ. Validation of CFD modelling of LH2 spread and evaporation against large-scale spill experiments. Int J Hydrogen Energy 2011; 36:26207. 
[13] Hanna SR, Hansen OR, Dharmavaram S. FLACS air quality CFD model performance evaluation with Kit Fox, MUST, Prairie Grass, and EMU observations. Atmos Environ 2004; 38: 4675-87.

[14] Hansen OR, Gavelli F, Ichard M, Davis S. Validation of FLACS against experimental data sets from the model evaluation database for LNG vapour dispersion. J Loss Prev Process Ind 2010; 23(6): 857-77.

[15] Ichard M, Hansen OR, Middha P, Willoughby D. CFD computations of liquid hydrogen releases. Int J Hydrogen Energy 2012; 37(22):17380-9.

[16] Venetsanos AG, Bartzis JG. CFD modeling of large-scale LH2 spills in open environment. Int J Hydrogen Energy 2007; 32(13):2171-7.

[17] Giannissi SG, Venetsanos AG, Markatos N, Bartzis JG. CFD modeling of hydrogen dispersion under cryogenic release conditions. Int J Hydrogen Energy 2014; 39(28):15851-63.

[18] Giannissi SG, Venetsanos AG. Study of key parameters in liquid hydrogen release and dispersion in open environment. Int J Hydrogen Energy 2018; 43(1):455-67.

[19] Verfondern K, Dienhart B. Experimental and theoretical investigation of liquid hydrogen pool spreading and vaporization. Int J Hydrogen Energy 1997; 22(7):649-60.

[20] Verfondern K, Dienhart B. Pool spreading and vaporization of liquid hydrogen. Int J Hydrogen Energy 2007; 32:2106-17.

[21] Jin T, Wu M, Liu Y, Lei G, Chen H, Lan Y. CFD modeling and analysis of the influence factors of liquid hydrogen spills in open environment. Int J Hydrogen Energy 2017; 42(1):732-9.

[22] Jin T, Liu Y, Wei J, Wu M, Lei G, Chen H, et al. Modeling and analysis of the flammable vapor cloud formed by liquid hydrogen spills. Int J Hydrogen Energy 2017;42(43):2676270.

[23] Liu Y, Wei J, Lei G, Lan Y, Chen H, Jin T. Dilution of hazardous vapor cloud in liquid hydrogen spill process under different source conditions. Int J Hydrogen Energy 2018; 43(15):7643-51.

[24] Liu Y, Wei J, Lei G, Wang T, Lan Y, Chen H, et al. Modeling the development of hydrogen vapour cloud considering the presence of air humidity. Int J Hydrogen Energy 2019;44(3):2059-68.

[25] Liu Y, Wei J, Lei G, Lan Y, Chen H, Gao X et al. Numerical investigation on the effects of dike around liquid hydrogen source on vapour cloud dispersion. Int J Hydrogen Energy 2019;44(10):5063-71.

[26] Liu Y, Wei J, Lei G, Chen H, Lan Y, Gao X et al. Spread of hydrogen vapor cloud during continuous liquid hydrogen spills. Cryogenics 2019;103:102975.

[27] Liu Y, Wei J, Liu Z, Lei G, Jin T. Dilution of flammable vapor cloud formed by liquid hydrogen spill. Int J Hydrogen Energy 2020; 45:5067-72.

[28] Shao X, Pu L, Li Q, Li Y. Numerical investigation of flammable cloud on liquid hydrogen spill under various weather conditions. Int J Hydrogen Energy 2018; 43:5249-60.

[29] Jakel C, Kelm S, Verfondern K, Allelein H. Validation of a 3D multiphasemulticomponent CFD model for accidental liquid and gaseous hydrogen releases. Int J Hydrogen Energy 2019;44(17):8807-18.

[30] Hansen O. Liquid hydrogen releases show dense gas behaviour. Int J Hydrogen Energy 2020; 45:1343-58.

[31] FLACS v10.8 User's Manual. GexCon AS; 2018.

[32] Patankar SV. Numerical Heat Transfer and Fluid Flow. Taylor \& Francis, 1980. 
[33] Pasquill F. The estimation of the dispersion of windborn material, Meteorol Mag 1961; 90(1063): 33-49.

[34] Golder D. Relations among stability parameters in the surface layer. Boundary-Layer Meteorol 1972; 3: 47-58.

[35] Han J, Arya SP, Shen S, Lin YL. An estimation of turbulent kinetic energy and energy dissipation rate based on atmospheric boundary layer similarity theory. NASA/CR-2000212298, 2000.

[36] Ivings MJ, Gant SE, Jagger SF, Lea CJ, Stewart JR, Webber DM. Evaluating vapor dispersion models for safety analysis of LNG facilities, The Fire Protection Research Foundation, National Fire Protection Association, USA, 2016.

[37] Hamdhan I, Clarke B. Determination of Thermal Conductivity of Coarse and Fine Sand Soils. In Proceedings World Geothermal Congress 2010, Bali, Indonesia, 25-29 April 2010, 1-7.

[38] NFPA 59A, Standard for the Production, Storage and Handling of Liquefied Natural Gas (LNG), National Fire Protection Association, 2016.

[39] Taylor, DW. The role of consequence modelling in LNG facility siting, J Hazard Mater 2007; 142: 776-85.

[40] Woodward JL, Pitblado, RM. LNG Risk Based Safety - Modeling and Consequence Analysis, AIChE, John Wiley \& Sons, USA, 2010.

[41] Giannissi SG, Venetsanos AG. A comparative CFD assessment study of cryogenic hydrogen and LNG dispersion, Int J Hydrogen Energy 2019; 44(17):9018-9030.

[42] BS EN 60079-10-1, Explosive Atmospheres Part 10-1: Classification of areas -Explosive gas atmospheres, British Standards Institute, 2015.

[43] NFPA 2, Hydrogen Technologies Code. National Fire Protection Association, 2016.

\section{Acknowledgements}

This work was carried out for the ENABLEH2 project funded by the European Union H2020 programme under GA no. 769241. 